\title{
Ventilation of the Mediterranean Sea constrained by multiple transient tracer measurements
}

\author{
T. Stöven and T. Tanhua \\ Helmholtz Centre for Ocean Research Kiel, GEOMAR, Kiel, Germany \\ Correspondence to: T. Stöven (tstoeven@geomar.de)
}

Received: 9 September 2013 - Published in Ocean Sci. Discuss.: 10 October 2013

Revised: 14 February 2014 - Accepted: 14 April 2014 - Published: 5 June 2014

\begin{abstract}
Ventilation is the primary pathway for atmosphere-ocean boundary perturbations, such as temperature anomalies, to be relayed to the ocean interior. It is also a conduit for gas exchange between the interface of atmosphere and ocean. Thus it is a mechanism whereby, for instance, the ocean interior is oxygenated and enriched in anthropogenic carbon. The ventilation of the Mediterranean Sea is fast in comparison to the world ocean and has large temporal variability. Here we present transient tracer data from a field campaign in April 2011 that sampled a unique suite of transient tracers $\left(\mathrm{SF}_{6}, \mathrm{CFC}-12,{ }^{3} \mathrm{H}\right.$ and $\left.{ }^{3} \mathrm{He}\right)$ in all major basins of the Mediterranean. We apply the transit time distribution (TTD) model to the data in order to constrain the mean age, the ratio of the advective/diffusive transport and the number of water masses significant for ventilation.

We found that the eastern part of the eastern Mediterranean can be reasonably described with a one-dimensional inverse Gaussian TTD (IG-TTD), and thus constrained with two independent tracers. The ventilation of the Ionian Sea and the western Mediterranean can only be constrained by a linear combination of IG-TTDs. We approximate the ventilation with a one-dimensional, two inverse Gaussian TTD (2IG-TTD) for these areas and demonstrate a possibility of constraining a 2IG-TTD from the available transient tracer data. The deep water in the Ionian Sea has a mean age between 120 and 160 years and is therefore substantially older than the mean age of the Levantine Basin deep water (6080 years). These results are in contrast to those expected by the higher transient tracer concentrations in the Ionian Sea deep water. This is partly due to deep water of Adriatic origin having more diffusive properties in transport and formation (i.e., a high ratio of diffusion over advection), compared to the deep water of Aegean Sea origin that still dominates the
\end{abstract}

deep Levantine Basin deep water after the Eastern Mediterranean Transient (EMT) in the early 1990s. The tracer minimum zone (TMZ) in the intermediate of the Levantine Basin is the oldest water mass with a mean age up to 290 years. We also show that the deep western Mediterranean has contributed approximately $40 \%$ of recently ventilated deep water from the Western Mediterranean Transition (WMT) event of the mid-2000s. The deep water has higher transient tracer concentrations than the mid-depth water, but the mean age is similar with values between 180 and 220 years.

\section{Introduction}

The Mediterranean Sea is a marginal sea, where the observational record shows significant changes in ventilation (Schneider et al., 2014). The most prominent transient event in the eastern Mediterranean Sea (EMed) is the transfer of the deep water source from the Adriatic Sea to the Aegean Sea and Sea of Crete and vice versa. The observed massive dense water input from the Aegean Sea and Sea of Crete in the early 1990s is known as the Eastern Mediterranean Transient (EMT) event (Roether et al., 1996; Klein et al., 1999; Lascaratos et al., 1999). The extensive deep water formation in the western Mediterranean Sea (WMed) between 2004 and 2006, known as the Western Mediterranean Transition (WMT) event (Schroeder et al., 2008, 2010), is thought to have been triggered by the EMT event (Schroeder et al., 2006). Nevertheless, both events are part of a general circulation pattern which can be observed in the Mediterranean Sea. The surface water in the WMed is supplied by less dense Atlantic water (AW) through the Strait of Gibraltar. The AW flows eastwards at depths $<200 \mathrm{~m}$ into the Tyrrhenian Sea 
and into the EMed via the Strait of Sicily. The salinity of the AW increases along the pathway from 36.5 to $>38$ due to net evaporation and is then described as modified Atlantic water (MAW) (Wuest, 1961). The heat loss during winter time in the MAW in the EMed leads to a sufficient increase of density to form the Levantine intermediate water (LIW) at depths between 200 and $600 \mathrm{~m}$ (Brasseur et al., 1996; Wuest, 1961). The exact area of the LIW formation process is poorly constrained and possibly variable, but it is expected to be in the eastern part of the EMed near Rhodes (Malanotte-Rizzoli and Hecht, 1988; Lascaratos et al., 1993; Roether et al., 1998). The main volume of the LIW flows back westwards over the shallow sill between Sicily and Tunisia entering the Tyrrhenian Sea along the continental slope of Italy (Wuest, 1961). Parts of the LIW enter the Adriatic Sea via the Strait of Otranto, where it serves as an initial source of the Adriatic Sea overflow water (ASOW). The formation of ASOW in the southern Adriatic pit is based on interactions between the LIW and water masses coming from the northern Adriatic Sea as well as the natural preconditioning factors, for example, wind stress and heat loss (Artegiani et al., 1996a, b). The ASOW flows over the sill of Otranto into the Ionian Sea intruding into the bottom layer and thus representing a source of eastern Mediterranean deep water (EMDW) (Schlitzer et al., 1991; Roether and Schlitzer, 1991). Furthermore, the Ionian Sea is connected with the Levantine Sea via the Cretan Passage, where portions of newly formed EMDW reach the deep water of the Levantine Sea. In 1992-1993, the water-mass conditions in the well-ventilated Aegean Sea and Sea of Crete changed into a more salty and cold state, sufficient enough to initialize the massive dense water input of Cretan deep water (CDW) into the abyssal basins of the EMed (Klein et al., 1999). This EMT event resulted in a disruption of the usual formation pattern of the EMDW. The Adriatic Sea as a major deep water source was thereby replaced by the Aegean Sea and Sea of Crete with the consequence that the bottom layer of the Ionian Sea was now supplied with dense water via the Antikythera Strait and the Levantine Sea via the Kasos Strait. The simultaneous dense water input into both basins, in conjunction with the large amount of the outflow, caused an uplift of the intermediate water layers in the Ionian and Levantine seas. One consequence of the EMT event seemed to be the preconditioning of the WMT event in 2004-2006 by uplifted water masses entering the WMed via the Strait of Sicily. However, the major triggering factor was the heat loss due to the mistral in the Gulf of Lion and the Balearic Sea, which resulted in the extensive deep water formation in the WMed. Although the total magnitude of the WMT event was smaller than the EMT event it was still sufficient to cause a near-complete renewal of the western Mediterranean deep water (WMDW). Recent water-mass analyses indicate, that the EMed is returning to a pre-EMT state with the Adriatic Sea as a major deep water source (Hainbucher et al., 2006; Rubino and Hainbucher, 2007).
The analysis of ventilation processes and their periodicity is an important issue in the understanding of their climate impact. Such analyses are not trivial, however, given the range of methods, views and concepts involved in understanding ventilation processes. For example, transient tracer distributions were used in the EMed by Roether et al. $(1996,2007)$ and in the WMed by Rhein et al. (1999) to quantify ventilation timescales. The time dependence of the transient tracers were used for first-age estimates based on simple approaches which provided an estimate of an apparent age or tracer age (Roether et al., 1998; Roether and Lupton, 2011). More complex age models, for example, the transit time distribution (TTD) model, account for the influence of mixing processes leading to a more realistic mean age estimate. A TTD related approach of age spectra modeling was carried out by Steinfeldt (2004) for the EMed in 1987, providing one of the first competing age estimates to the tracer age approach. The TTD model was, more recently, used for a time-series analysis of the entire Mediterranean Sea by Schneider et al. (2014). Such concepts of age and timescales in the ocean can also contain commonly used parameters like volume fluxes (changes) per time unit, normally stated as ventilation rate as well as residence time, influence time, tracer age, apparent age and mean age. Some of these parameters are occasionally presented in different contexts and meanings, leading to controversial discussions (Delhez et al., 2013). However, this paper does not include quantitative statements about ventilation rates or residence times. This study was focused on providing methods to constrain the mean age of the Mediterranean Sea within the framework of TTD models, which were then used to describe ventilation in terms of "age" structure and further qualitative characteristics, such as the advective and diffusive behavior of the different water masses. To this end, measurements of the transient tracers dichlorodifluoromethane (CFC-12) and sulfur hexafluoride $\left(\mathrm{SF}_{6}\right)$ as well as helium isotopes $\left({ }^{3} \mathrm{He}\right.$, $\left.{ }^{4} \mathrm{He}\right)$ and tritium $\left({ }^{3} \mathrm{H}\right)$ were carried out during the Meteor expedition M84/3 in 2011 yielding a comprehensive data set of time dependent tracers (Fig. 1). The insights gained in this TTD model application method should also provide possible improvements for continuative estimates of ventilation rates, defined by Primeau and Holzer (2006); Hall et al. (2007) and anthropogenic carbon contents (Tanhua et al., 2008).

\section{Materials and method}

\subsection{Transient tracers}

\subsubsection{Chronological transient tracers}

The uses of chronological transient tracers, such as chlorofluorocarbons (CFCs) and $\mathrm{SF}_{6}$ to estimate the age of a water mass are based on an increasing tracer concentration in the atmosphere. Concentrations of trace gases in the atmosphere are, for example, measured continuously by the world-wide 


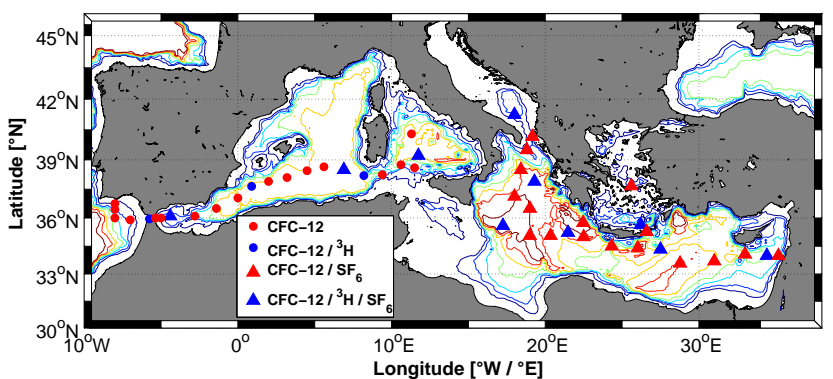

Figure 1. Transient tracer sample stations of the M84/3 cruise from Istanbul to Vigo. Triangles indicate stations including $\mathrm{SF}_{6}$ measurements and a blue color coding indicates tritium measurements. CFC-12 was measured at all stations on this map. The depth contours are $500: 500: 3500$.

AGAGE network, so that the emission history and atmospheric variations over time are well known (Walker et al., 2000; Bullister, 2011), which then provide the tracer's input functions. The production of CFCs, and ultimately their emissions, were decreased in the late 1980s and then finally stopped in the 1990s as a result of the Montreal Protocol. This has resulted in a steady decrease of atmospheric CFC-12 concentrations such that in 2011 the concentration was $532 \mathrm{ppt}$ (Bullister, 2011). Because the concentrations of CFC-12 in the atmosphere were increasing prior to the 1990s and then decreased up until 2011, CFC-12 concentrations in seawater that are higher than the 2011 atmospheric concentration could therefore represent one of two dates (i.e., before the 1990s or after the 1990s, Fig. 2). To this end, CFC-12 concentrations are inconclusive for tracer age determination between 1994 and 2011. SF 6 concentrations are still increasing approximately linearly but the emission rate is relatively low so that the concentration in the atmosphere is reportedly below 8 ppt. Some local restrictions are in place for the production and use of $\mathrm{SF}_{6}$, but an international agreement has yet to be reached, despite its global warming potential of 22000 (Houghton et al., 1996). Tracers enter the ocean's surface layer via gas exchange and the solubility is a function of temperature, salinity and the physical nature of the molecule. Solubility functions are available for most of the CFCs and $\mathrm{SF}_{6}$ (Warner and Weiss, 1985; Bullister et al., 2002) and are used to convert the measured gravimetric units (e.g., pmol kg-1 for CFC-12 and fmol kg ${ }^{-1}$ for $\mathrm{SF}_{6}$ ), into the partial pressure (ppt) of the tracer. The partial pressure is the preferred choice since it is independent of pressure, salinity and temperature and thus directly comparable within the complete water column and atmosphere.

Chronological tracers are conserved tracers with no significant sources or sinks in the ocean interior. The concentration in the water column depends on the last time the water parcel was in contact with the atmosphere and on the influence of mixing and diffusion.

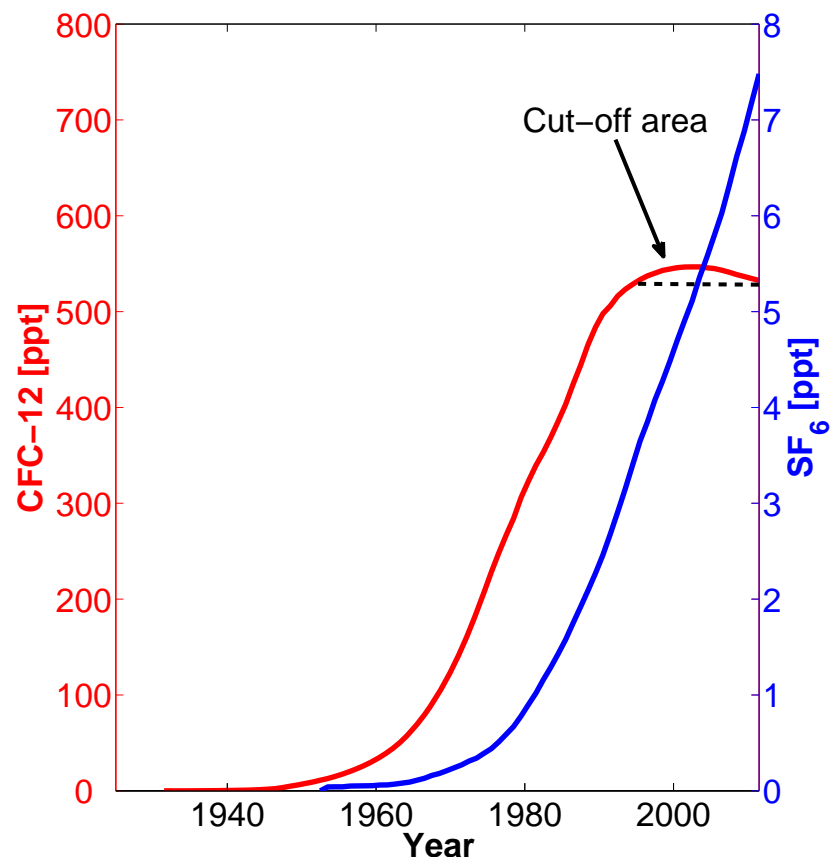

Figure 2. Atmospheric histories of CFC-12 (red) and of $\mathrm{SF}_{6}$ (blue). The decreasing trend of CFC-12 produces a cut-off area between 1994 and 2011, which means that any CFC-12 concentration above $532 \mathrm{ppt}$ provides only inconclusive information about ventilation.

\subsubsection{Radioactive transient tracers}

The radioactive tracers such as tritium and its decay product helium-3 $\left({ }^{3} \mathrm{He}\right)$ form the second class of transient tracers. Tritium has a natural background concentration of $\approx 0.3$ tritium units (TU) in the atmosphere, where $1 \mathrm{TU}$ equals the number of one tritium atom per $10^{18}$ hydrogen atoms (Ferronsky and Polyakov, 1982). Due to nuclear bomb tests in the late 1950s and 1960s, the tritium concentration increased up to $100 \mathrm{TU}$ in the atmosphere and declined afterwards to a current concentration of 1-1.2 TU in 2011 (Roether et al., 2013). The input of tritium into the ocean surface layer is a function of radioactive decay in the atmosphere, vapor pressure, the variance of location and magnitude of precipitation and fresh water flux by riverine input. Tritium decays to helium3 , known as tritiugenic helium-3 $\left({ }^{3} \mathrm{He}_{\text {trit }}\right)$ which equilibrates with the atmosphere as long as the water parcel remains in the boundary layer of gas exchange. Once the water reaches the oceans interior, radioactive decay serves as time varying sink. However, the total concentration of helium-3 $\left({ }^{3} \mathrm{He}_{\text {tot }}\right)$ in sea water consists of several shares of different sources. The determination of the ${ }^{3} \mathrm{He}_{\text {trit }}$ share requires the knowledge of excess helium-3 $\left({ }^{3} \mathrm{He}_{\mathrm{ex}}\right)$, that is, the surface saturation and the terrigenic share $\left({ }^{3} \mathrm{He}_{\text {terr }}\right)$ from the earth crust and mantle (i.e., the sea floor as source of ${ }^{3} \mathrm{He}$ ).

The Mediterranean is characterized by higher tritium concentrations than the Atlantic due to continental influences in terms of weather conditions and fresh water input. A 
commonly used tritium input function (TIF) for the North Atlantic was obtained by Dreisigacker and Roether (1978) and further developed for the EMed by Roether et al. (1992). Based on this data set, another TIF for the EMed was created by R. Steinfeldt (unpublished data) where the data after 1974 was extrapolated by using the decay function of tritium. In the WMed the surface layer is mainly influenced by the inflow of Atlantic water (AW), so that the input function needs to be corrected for the degree of dilution. The difference between the mean surface tritium concentration of the M84/3 cruise and the concentration value of the TIF by R. Steinfeldt (unpublished data) of the same year can be used to determine correction factors for the eastern and western Mediterranean. Under the assumption that the determined offset is constant over years, both factors can be used as an offset correction to create two alternative input functions (Fig. 3) which can be applied to a TTD mixing model (see below). The corrected TIFs have a surface (input) concentration which is $15 \%$ lower in the EMed and 35\% lower in the WMed than suggested in the original input function. Figure 3 shows the recent TIF of the Mediterranean Sea by Roether et al. (2013), which also relies on the data set of Dreisigacker and Roether (1978). This TIF was recalculated for the EMed by using a dilution factor and mean surface tritium concentrations obtained during several cruises between 1974 and 2011. Comparing both recent TIFs of the EMed shows that the shape of both curves is relatively similar. This indicates that both input functions seem to be useful approaches for the EMed despite the different methods used in their estimation. However, by using an interpolated form of the input function of Roether et al. (2013), a higher mean age is yielded compared to the input function we obtained. The main deviation from the decay-based input function is the data point of 1978, following that the interpolated tritium concentrations were significantly elevated between 1975 and 1987, producing differences in mean age. The mean deviation between the different TIFs and the original TIF of the North Atlantic are $86 \%$ and $61 \%$, respectively (Roether et al., 2013), for the EMed and $43 \%$ for the WMed.

\subsection{Tracer age and the transit time distribution}

The age of a water parcel can be described in different ways. For chronological transient tracers, the measured concentration of sample $c$ in year $t_{\mathrm{s}}$ (year of sampling) can be set in relation to the same concentration $c_{0}$ with the relevant year $t_{\text {hist }}$ of the atmospheric history of the tracer (Eq. 1).

$c\left(t_{\mathrm{s}}\right)=c_{0}\left(t_{\text {hist }}\right)$

The difference between the year of sampling $t_{\mathrm{s}}$ and the obtained year $t_{\text {hist }}$ defines the tracer age $\tau$ (Eq. 2).

$\tau=t_{\mathrm{s}}-t_{\mathrm{hist}}$

The tracer age of radioactive tracers depends on first order kinetics shown in Eq. (3). The initial concentration $c_{i}$, the in

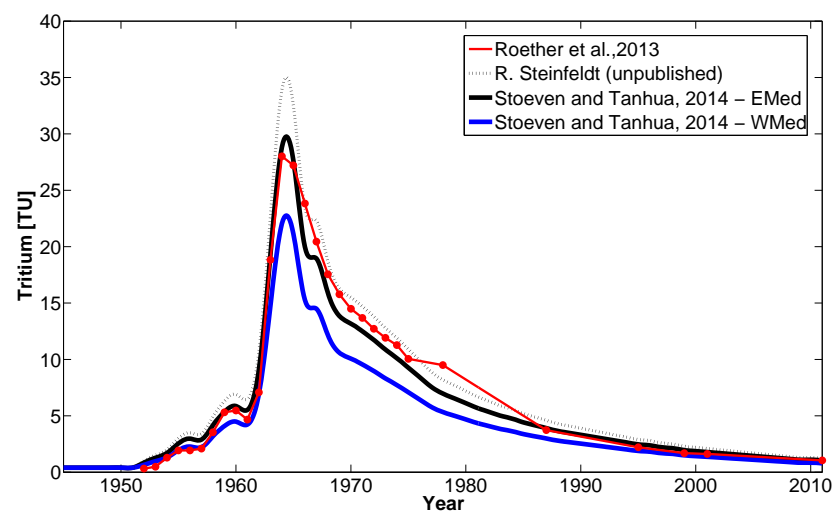

Figure 3. Input functions of tritium. The dotted black curve shows the decay based input function of the Mediterranean Sea by R. Steinfeldt (unpublished data). The black and blue curves describe the off set corrected input functions for the eastern and western Mediterranean Sea. The red curve shows the suggested input function by Roether et al. (2013) of the eastern Mediterranean Sea.

situ concentration $c$ and the decay constant $\lambda$ are the required parameters to calculate the elapsed time of a tracer in a water parcel.

$\tau=\frac{1}{\lambda} \cdot \ln \left(\frac{c_{\mathrm{i}}}{c}\right)$

As mentioned above, tritium has, in addition to the radioactive decay, a relevant input function and thus an unknown part for $c_{\mathrm{i}}$. Therefore, the share of ${ }^{3} \mathrm{He}_{\text {trit }}$ needs to be determined which replaces the initial concentration of tritium and Eq. (3) can be rewritten as Eq. (4). A generally accepted value for the decay constant of tritium is $\lambda=0.05576 / a$ (Unterweger et al., 1980; Taylor and Roether, 1982).

$\tau=\frac{1}{\lambda} \cdot \ln \left(1+\frac{\left[{ }^{3} \mathrm{He}_{\text {trit }}\right]}{\left[{ }^{3} \mathrm{H}\right]}\right)$

The informative value of a tracer age is relatively low because it is based on the assumption of a complete advective behavior neglecting any diffusive mixing process. However, there are also methods such as dilution models (Roether et al., 2013) and the tracer age of CFC-12 and $\mathrm{SF}_{6}$ with a $\approx 14$ year time lag (Tanhua et al., 2013c; Schneider et al., 2014) that allow an estimation of changes in ventilation.

The TTD model is based on the Green's function and was invented to describe atmospheric ventilation processes (Hall and Plumb, 1994). However, the basic idea that a parcel of molecules changes its location under the influence of advection and diffusion can also be applied to ventilation processes of the ocean. Equation (5) is an analytical expression of the Green's function which provides access to use field data within the TTD model (Waugh et al., 2003). It is based on a one-dimensional flow model with constant advective velocity and diffusivity and is therefore known as 
the one-dimensional inverse Gaussian transit time distribution (IG-TTD)

$$
G(t)=\sqrt{\frac{\Gamma^{3}}{4 \pi \Delta^{2} t^{3}}} \cdot \exp \left(\frac{-\Gamma(t-\Gamma)^{2}}{4 \Delta^{2} t}\right)
$$

The key variables in this equation are $\Gamma$ for the mean age and $\Delta$ for the width of the distribution. The age spectra $t$ is defined by the initial year $t_{\mathrm{i}}$ of the atmospheric history or the input function of the tracer and the year of sampling $t_{\mathrm{s}}$. To give a statement on the share of advection and diffusion, the $\Delta / \Gamma$ ratio can be used. A low ratio, such as $0.4-0.8$, indicates a high advective part (e.g., extensive deep water formations), whereas a high ratio like $1.2-1.8$ indicates a more diffusive character of the water parcel. The definite integral of Eq. (6) contains the link between the measured concentration of a sample $c\left(t_{\mathrm{S}}\right)$ and the mean age of the TTD. The parameter $r$ describes the location of the water parcel, $t-$ the time range of the tracer and $e^{-\lambda t}-$ the decay correction for radioactive transient tracers.

$c\left(t_{\mathrm{s}}, r\right)=\int_{0}^{\infty} c_{0}\left(t_{\mathrm{s}}-t\right) e^{-\lambda t} \cdot G(t, r) \mathrm{d} t$

A further approach to determine a mean age is the linear combination of two distributions which is shown in Eq. (7). Hereby, $\alpha$ describes the percentage ratio between the two Gfunctions. Such a two inverse Gaussian TTD (2IG-TTD) can be envisioned for two water masses with different histories (age), but with similar density, that mixes in the ocean interior. This model has been explored by, for instance, Waugh et al. (2002).

$$
\begin{aligned}
c\left(t_{\mathrm{s}}, r\right) & =\int_{0}^{\infty} c_{0}\left(t_{\mathrm{s}}-t\right) e^{-\lambda t} . \\
& {\left[\alpha G\left(\Gamma_{1}, \Delta_{1}, t, r\right)+(1-\alpha) G\left(\Gamma_{2}, \Delta_{2}, t, r\right)\right] \mathrm{d} t }
\end{aligned}
$$

The number of possible combinations of distributions and parameters provides a comprehensive concept of age modeling in the ocean. The main complexity consists of finding accurate and reasonable solutions related to the field data. The mean age is then determined by Eq. (8), whereas $\Gamma_{1}$ and $\Gamma_{2}$ are the partial mean age results of each $\mathrm{G}$-function.

$\Gamma=\alpha \cdot \Gamma_{1}+(1-\alpha) \cdot \Gamma_{2}$

\subsection{Practical application of the TTD model}

A common procedure described in several published articles (e.g., Schneider et al., 2010; Waugh et al., 2006, 2004) is to apply the IG-TTD with a ratio of $\Delta / \Gamma=1.0$ to the tracer data to calculate a water-mass mean age. The $\Delta / \Gamma$ ratio has been demonstrated to be close to 1 in large parts of the world ocean (i.e., established as standard ratio). This standard ratio can be used to analyze transient tracer time series in terms of changes in ventilation, where the rate of age growth $\mathrm{yr}^{-1}$ is more in focus than a precise mean age (Huhn et al., 2013). The recently published work by Schneider et al. (2014) is also based on the standard ratio of $\Delta / \Gamma=1.0$, which allows a comparison to be made between all data sets and thus an analysis of changes during the period of interest. In the case of a time series, it is rarely possible to apply similar constraints to different data sets. The standard ratio should also be used within tracer surveys with only few sample points because local outliers of constrained data points can produce significant flaws in interpolation. For a comprehensive data set, consisting of more than one transient tracer, a constrained TTD model provides an alternative. The determined $\Delta / \Gamma$ ratios provide a first insight into the water-mass structure concerning the advective and dispersive behavior. The further analysis of ventilation processes, rates and recent changes in water masses as well as the estimation of the anthropogenic carbon column inventory is based on the determined mean age and thus dependent on the exact $\Delta / \Gamma$ ratio. However, it is an important principle to identify in which manner a TTD method was applied before comparing different studies.

\subsubsection{Constraining the IG-TTD model}

There have been several approaches made to constrain a TTD model. For instance, Waugh et al. (2002) uses the lower and upper mean age limit of the transient tracers and plot them against the standard deviation $(\sigma)$ of the TTD. In the case of an IG-TTD it can be approximated as $\Delta=\sigma / \sqrt{2}$. The area which is spanned by all tracers then constrain the TTD. Other methods are based on property-property plots. For example are tracer concentrations plotted against each other including predicted concentration curves by the TTD for different $\Delta / \Gamma$ ratios, whereas the best fit of a predicted curve to the bunch of data provides a single overall constraint of the TTD (Waugh et al., 2004). A similar method is used by Schneider et al. (2012) where the CFC-12 mean age is plotted vs. the $\mathrm{SF}_{6}$ mean age for different $\Delta / \Gamma$ ratios. Hereby, a good correlation between the data points and the bisecting line (slope $=1$ ) denotes the ideal ratio. However, each method to constrain a TTD requires a transient tracer couple. The tracers of the couple need to have sufficiently different input functions to constrain the $\Delta / \Gamma$ ratio. Tracer couples with similar atmospheric histories (e.g., CFC-12 and CFC11) will yield a wide range of possible outcomes and will result in a poorly constrained TTD. Useful couples are CFC$12-\mathrm{SF}_{6}$ and tritium- $\mathrm{SF}_{6}$.

Our approach is based on constraining single data points instead of determining an overall $\Delta / \Gamma$ ratio. Therefore, the first step of data processing includes the calculation of the mean age for $\Delta / \Gamma$ ratios between 0.0 and 1.8 for every data point and tracer, always taking into account the correct input function of the source region. The determined data points of mean age vs. $\Delta / \Gamma$ ratio are used to obtain second-order 


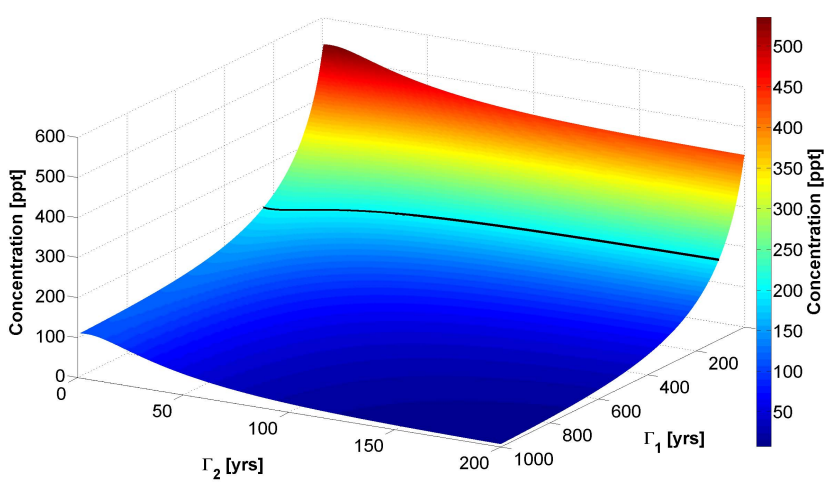

Figure 4. Example mean age matrix of CFC-12 with $\Delta_{1} / \Gamma_{1}=1.4$, $\Delta_{2} / \Gamma_{2}=0.6$ and $\alpha=80$. The color-coding denotes the concentration of CFC-12 (in ppt, also on the $z$ axis) with a black concentration contour line at $200 \mathrm{ppt} ; x$ and $y$ axis denotes the mean age of the 2IG distributions that make up the TTD. The combination of all three-dimensional tracer matrices provides the needed information to constrain a 2IG-TTD, see text.

polynomial regressions. Following this, every sample point of every tracer can be expressed by a mean age function (Eq. 9).

$$
\Gamma=a\left({ }^{\Delta} / \Gamma\right)^{2}+b\left({ }^{\Delta} / \Gamma\right)+c
$$

The intersection between two mean age functions denotes the constrained $\Delta / \Gamma$ ratio and mean age. In some cases where no exact intersection can be found it is useful to determine the local minimum of a combined mean age function in the range of $\Delta / \Gamma$. A local minimum indicates the point of the smallest difference in mean age, which should be used to a maximum difference of 5 years to ensure also the consideration of a mean analytical error of $\approx 4 \%$ (see below). To obtain the mean age of such a minimum function, the average of both mean age values needs to be calculated. However, in some cases it is more meaningful to use one of the tracer's mean age rather than the average mean age. For example, the $\mathrm{SF}_{6}$ mean age for recently ventilated waters is more significant than the CFC-12 mean age due to the recent non-transient input function of CFC-12. In contrast, the CFC-12 mean age should be used in older water layers where $\mathrm{SF}_{6}$ concentrations are close to the detection limit (Tanhua et al., 2008).

A further aspect of the IG-TTD model is the validity area of each tracer couple, which defines the possible range of IGTTD solutions. A rough classification of the specific validity area of a couple can be done by determining the tracer age differences. For example, if the difference of the tracer age between $\mathrm{SF}_{6}$ and $\mathrm{CFC}-12$ is large (10 years for the sampling year of 2011), it indicates that an IG distribution cannot explain the tracer distribution, and more refined models of the TTD are needed, for instance the linear combination of two IG-TTDs.

\subsubsection{Constraining the 2IG-TTD model}

Due to the five free parameters $\alpha, \Gamma_{1}, \Gamma_{2}, \Delta_{1}$ and $\Delta_{2}$, the system of equations is under-determined for any tracer survey with less than five measured transient tracers. Most surveys include two or three transient tracers with sufficiently different atmospheric histories. Here we introduce one way to use an under-determined 2IG-TTD model. Based on oceanographic water-mass analysis one can estimate the composition of the current state of the water masses and roughly the underlying mixing processes. As described earlier, the western and eastern Mediterranean are both affected by an extensive deep water formation with recently ventilated and salty water from the surface and intermediate layers, respectively. The null hypothesis is that an old and more stationary water mass can be described by an IG-TTD which has been intruded by a younger water parcel described by another IG-TTD. Hereby the younger water parcel might be characterized by a more advective behavior with a low ratio (e.g., $\Delta / \Gamma=0.6)$. The ratio of the more stationary water mass is set to $\Delta / \Gamma=1.4$, describing a typical ratio of a more diffusive/dispersive behavior. By making assumptions about the $\Delta / \Gamma$ ratio of both IG-TTDs one can calculate mean age matrices for different $\alpha$ 's with $x=\Gamma_{1}, y=\Gamma_{2}$ and $z=C_{\text {tracer }}$. The concentration of a measured sample generates different concentration curves for each $\alpha$ in the $x-y$ plane (Fig. 4). The predefined 2IG-TTD is constrained if there is an intersection area of the concentration curves of different tracers describing one mean age (Eq. 8).

\subsection{Sampling and measurements}

The expedition M84/3 from Istanbul (Turkey) to Vigo (Spain) took place from the 5 to 28 April in 2011 on the German research vessel FS Meteor (Tanhua et al., 2013a, b). Figure 1 shows an overview of the sample stations with different symbols denoting which tracers were measured. The transient tracers $\mathrm{CFC}-12$ and $\mathrm{SF}_{6}$ were sampled at nearly all stations in the EMed, whereas only three stations of $\mathrm{SF}_{6}$ exist in the WMed. Tritium was sampled at 7 stations in the EMed and 6 stations in the WMed. The sampling depths were chosen to cover the most important water layers in a sufficient resolution. Starting with an minimum sampling depth increment of $25 \mathrm{~m}$ in the surface and mixed layer and ending with a maximum increment of $500 \mathrm{~m}$ in the deep water layers (see Table 1).

\subsubsection{CFC-12 and $\mathrm{SF}_{6}$}

The measurements of CFC-12 and $\mathrm{SF}_{6}$ were mainly performed on board. The water samples were taken with $250 \mathrm{~mL}$ glass syringes or $300 \mathrm{~mL}$ glass ampules, under exclusion of atmosphere, from the Niskin bottles. The syringes and ampules were stored in a cooling box filled with water of $\approx 0{ }^{\circ} \mathrm{C}$ to prevent outgasing of the tracers. The measurements were 
Table 1. Standard sampling depths of the M84/3 cruise in 2011.

\begin{tabular}{ll}
\hline Increment $[\mathrm{m}]$ & Depth range $[\mathrm{m}]$ \\
\hline 25 & $0-100$ \\
50 & $100-300$ \\
100 & $300-600$ \\
200 & $600-1000$ \\
250 & $1000-2500$ \\
500 & $2500-$ bottom \\
\hline
\end{tabular}

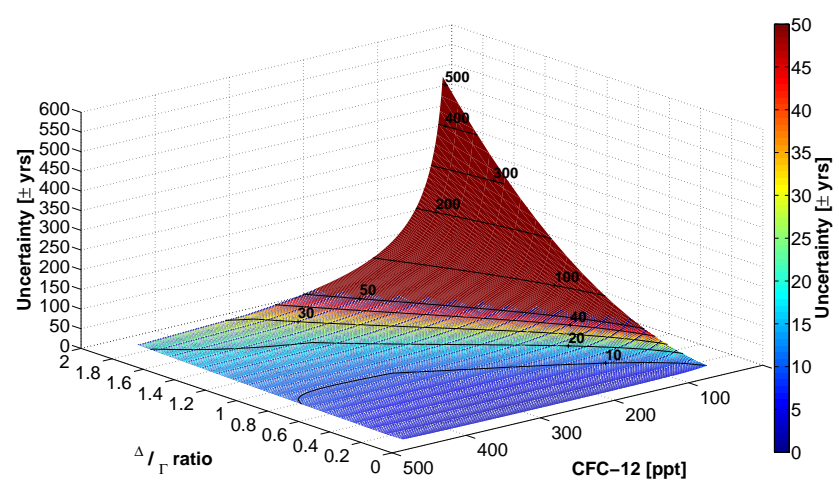

carried out with similar analytical systems as described by Bullister and Wisegarver (2008) and Law et al. (1994). The first measurement system named VS1 consisted of a Shimadzu GC14a gas chromatograph equipped with an electron capture detector (ECD), stainless steel tubing system and Valco valves. An evacuated vacuum sparge tower (VST) was used to transfer the water sample out of the glass ampule into the measurement system. Due to the low pressure in the VST, most of the dissolved gases pass over into the head space during the filling process. The residual was purged out with nitrogen (ECD-quality). The analytes were trapped on a $1 / 16^{\prime \prime}$ column packed with $70 \mathrm{~cm}$ Heysep $D$ and then separated with a $1 / 8^{\prime \prime}$ precolumn, packed with $30 \mathrm{~cm}$ Porasil $C$ and a $1 / 8^{\prime \prime}$ main column consisting of $180 \mathrm{~cm}$ Carbograph $1 A C$ and a $20 \mathrm{~cm}$ Molsieve $5 \AA$ tail end. The trap was installed in a Dewar filled with a bottom layer of liquid nitrogen. The distance between trap and cooling medium was regulated by a Lab Boy to hold a temperature range between -70 and $-60^{\circ} \mathrm{C}$ during the purge process. Due to some problems with the VS1 system and a sudden break down of the ECD several samples from key stations have been flame sealed in glass ampules for a later onshore measurement. The sealed ampules were measured during summer 2011 at the IfMGEOMAR in Kiel with the repaired VS1 instrument and an installed ampule cracker system similar to Vollmer and Weiss (2002).

The second measurement system PT3 consisted of a Shimadzu GC2014 gas chromatograph with a similar basic setup like the VS1 system but with a different column composition, sample chamber and trap system. The $1 / 8^{\prime \prime}$ precolumn consisted of $60 \mathrm{~cm}$ Porasil $C$ and $10 \mathrm{~cm}$ Molsieve $5 \AA$, the $1 / 8^{\prime \prime}$ main column of $180 \mathrm{~cm}$ Carbograph $1 A C$ and $30 \mathrm{~cm}$ Molsieve $5 \AA$. Insufficient base line separation prevented a quantitative analysis of $\mathrm{SF}_{6}$ with this column setup. For each measurement, an aliquot of $\approx 200 \mathrm{~mL}$ was injected into the sample chamber with a sampling syringe and then purged with high purified nitrogen. A pressure regulated ethanol bath was used for keeping the trap cold. The ethanol was cooled by a Julabo cooling finger to a minimum temperature of $-68{ }^{\circ} \mathrm{C}$. For the purge and trap process the fill level is raised until the trap dips into the ethanol and is lowered again for the heating process (Bullister and Wisegarver, 2008). The traps of both measurement systems were heated to $90^{\circ} \mathrm{C}$

Figure 5. Absolute error of mean age calculations depending on CFC-12 concentrations and $\Delta / \Gamma$ ratios. The color coding is restricted to a maximum of 50 years for an improved error resolution of the main area.

by an electrical current flow, which was automatically regulated by a proportional-integral-derivative controller (PID). A detailed description of the data set, the sampling, the calibration and measuring procedure including chromatograms and the specific retention times as well as a precise technical overview can be found in the published diploma thesis by Stöven (2011).

\subsubsection{Tritium}

Water samples for tritium measurements were taken in $1 \mathrm{~L}$ plastic bottles and sent to the Institute of Environmental Physics at the University of Bremen where the samples were degassed and stored for several weeks to accumulate ${ }^{3} \mathrm{He}_{\text {trit }}$. The measurements of the tritiugenic helium isotopes were then carried out with a sector field mass spectrometer. Details of the measuring procedure and statistical evaluations can be found in Sültenfuß et al. (2009) and the results are described in Roether et al. (2013).

\subsubsection{Uncertainties}

The precisions of CFC-12 and $\mathrm{SF}_{6}$ measurements from both instruments can be found in Table 2. The error of calibration routines, that is, standard gas, standard loops, temperature and pressure, is $\approx 1 \%$. The uncertainty of the purge efficiency of CFC- 12 is estimated to be $2 \%$ and negligible low for $\mathrm{SF}_{6}$ so that the accuracy of CFC-12 is approximately $3 \%$ and $1 \%$ for $\mathrm{SF}_{6}$. The uncertainty of the atmospheric history is $<1 \%$ for $\mathrm{SF}_{6}$ and $\mathrm{CFC}-12$, whereas for low concentrations of CFC-12 an error of $\leq 4 \%$ should be assumed due to the time period prior reliable CFC measurements (Tanhua et al., 2008; Walker et al., 2000). The input functions depend on the degree of saturation during a water-mass formation which is influenced by wind speed, mixed layer depth, convection velocity, pressure and temperature drops as well as the atmospheric emission increase of a tracer, resulting in an approximate $10 \%$ propagation of uncertainty (Haine 


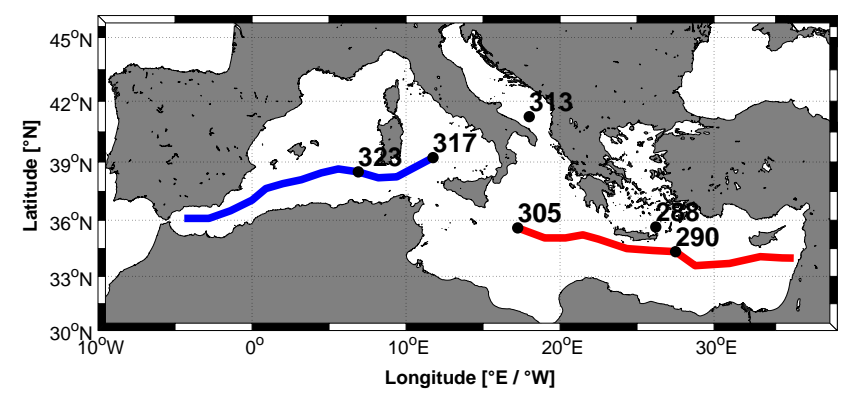

Figure 6. Sections and key stations of the transient tracer analysis. The red line shows the EMed section, the blue line the WMed section and the black dots the key stations.

and Richards, 1995; DeGrandpre et al., 2006; Tanhua et al., 2008). Furthermore, there are some regions were $\mathrm{SF}_{6}$ has been used for release experiments (e.g., 1996 in the Greenland Sea gyre; Watson et al., 1999), which could produce an offset in concentrations. Since 2006 it is recommended to use an alternative tracer for release experiments to avoid such interferences with $\mathrm{SF}_{6}$ of atmospheric origin. However, there was a release experiment using 1.327 mole of $\mathrm{SF}_{6}$ in the Gulf of Lion in 2007 within the Lagrangian transport experiment (LATEX) (Hu et al., 2009). The $\mathrm{SF}_{6}$ was released at shallow depths and it can be assumed that most of the $\mathrm{SF}_{6}$ will be ventilated to the atmosphere, but nonetheless it is a possible error source with an unknown impact on further $\mathrm{SF}_{6}$ surveys in this region. Assuming the worst case scenario of a deep water formation within this $\mathrm{SF}_{6}$ patch, for example, the WMT event with a water renewal volume of $\approx 1.5 \times 10^{14} \mathrm{~m}^{3}$ (Schroeder et al., 2008), the interior concentration of $\mathrm{SF}_{6}$ would be elevated by $0.009 \mathrm{fmol} \mathrm{kg}^{-1}$ which is negligible.

The error of tritium measurements is given as $\pm 3 \%$ and $\pm 0.02 \mathrm{TU}$ whichever is greater (Roether et al., 2013). The input functions of tritium are in contrast to the atmospheric histories of CFC-12 and $\mathrm{SF}_{6}$ not well documented and have several regional influencing factors as already mentioned above. An uncertainty of up to $15 \%$ might be a realistic estimate of the used input functions.

The uncertainties in mean age is a function of errors in transient tracer concentrations and the $\Delta / \Gamma$ ratio. Figure 5 shows an example for absolute errors in mean age calculations based on CFC-12. The mean age becomes more uncertain for low tracer concentrations and high $\Delta / \Gamma$ ratios. The error functions for $\mathrm{SF}_{6}$ and tritium are similar to the one of CFC-12.
Table 2. Precision of CFC-12 and $\mathrm{SF}_{6}$ measurements.

\begin{tabular}{lll}
\hline & \multicolumn{2}{c}{ Precision } \\
\cline { 2 - 3 } System & $\mathrm{SF}_{6}$ & CFC-12 \\
\hline VS1 & $\pm 1.4 \% / \pm 0.05 \mathrm{ppt}$ & $\pm 0.6 \% / \pm 2 \mathrm{ppt}$ \\
PT3 & - & $\pm 0.3 \% / \pm 1 \mathrm{ppt}$ \\
Cracker & $\pm 4.3 \% / \pm 0.07 \mathrm{ppt}$ & $\pm 1.9 \% / \pm 5 \mathrm{ppt}$ \\
\hline
\end{tabular}

\section{Results and discussion}

\subsection{General ventilation pattern}

\subsubsection{Eastern Mediterranean Sea}

The zonal sections of the transient tracer concentrations of the Ionian and Levantine seas show some significant characteristics of their ventilation (Figs. 6, 7). Between $27^{\circ} \mathrm{E}$ and the coast of Lebanon, a clear tracer minimum zone (TMZ) can be identified by all three tracers which vertically spreads from approximately 700 to $1600 \mathrm{~m}$ depths. The core concentration of the TMZ is $106 \mathrm{ppt}$ for CFC-12, $0.3 \mathrm{ppt}$ for $\mathrm{SF}_{6}$ and $0.3 \mathrm{TU}$ for tritium, whereas the lowest values are not visible in the gridded fields shown in Fig. 7. Beneath this TMZ, the tracer concentrations are elevated in the deep water due to the deep water formation in the eastern Mediterranean Sea that led to a high volume input of tracer rich and dense water masses. The bottom concentration of the tracers are $\approx 200 \mathrm{ppt}$ for $\mathrm{CFC}-12, \approx 1.1 \mathrm{ppt}$ for $\mathrm{SF}_{6}$ and $\approx 0.6 \mathrm{TU}$ for tritium. In the westerly parts of the section (i.e., the deep Ionian Sea), the tracer concentration is higher in the deep and bottom layer than in the east. This water-mass characteristic belongs to recent intrusions of ASOW coming from the deep water source in the Adriatic Sea. Station 313 in the southern Adriatic pit can be used as representative example for the source region of the ASOW. The concentration profiles show, that the southern Adriatic pit is a well-mixed and ventilated basin with minimum tracer concentrations of CFC$12>429$ ppt, $\mathrm{SF}_{6}>5 \mathrm{ppt}$ and tritium $>0.9 \mathrm{TU}$ (Fig. 8a). The high concentrations of CFC-12 and tritium throughout the entire water column at station 288 in the Sea of Crete can be related to the time range from the 1990s until the present day (Fig. 8b). The concentration gradient of $\mathrm{SF}_{6}$, however, indicates a recent return to a more layered structure in the Sea of Crete, so that the high concentrations of CFC-12 and tritium in the intermediate and deep water have to be formed before this layering process, probably during the 1990s. This would imply that the EMT source region was a completely mixed basin during the outflow event. This difference in tracer structures is related to the increasing input function of $\mathrm{SF}_{6}$ and the weak input functions of $\mathrm{CFCs}$ since the early 1990s (i.e., the onset of the EMT). CFC12 and tritium concentrations cannot be used to identify the recent change in ventilation of the Sea of Crete. A further 


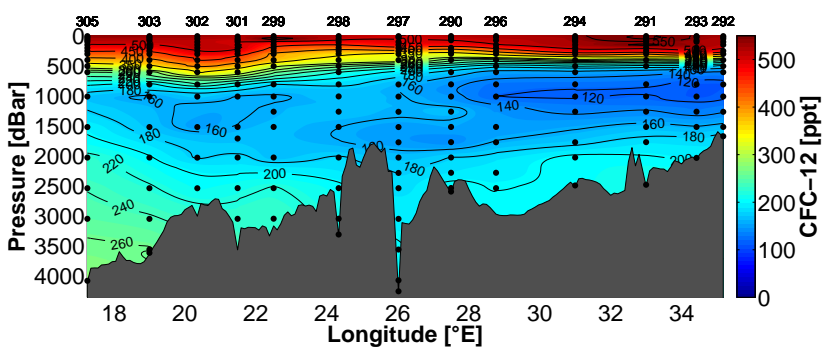

(a)

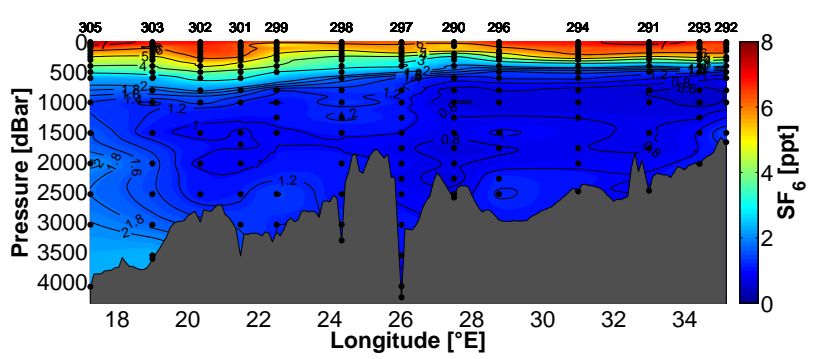

(b)

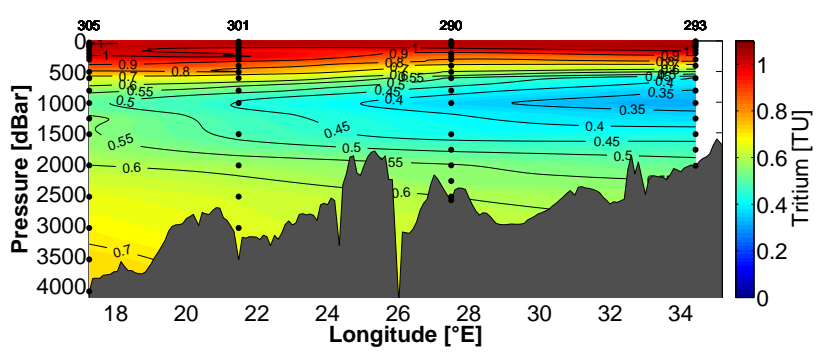

(c)

Figure 7. Transient tracer concentrations in the EMed during April 2011 (cruise M84/3), red line in Fig. 6. (a) CFC-12 in ppt, (b) SF6 in ppt and (c) tritium in TU.

aspect is the distribution of $\mathrm{SF}_{6}$ in the Ionian and Levantine seas which looks more homogeneous in the intermediate and deep water compared to CFC-12. This is based on the relatively young atmospheric history of $\mathrm{SF}_{6}$, leading to deep water masses which are only less affected by this tracer. Accurate measurements between $1 \mathrm{ppt}$ and the detection limit are needed to have a useful resolution. As mentioned above, CFC-12 has a long atmospheric history with a rapid concentration increase over several decades. Thus, CFC-12 has a large dynamic scale within the measurement range, so that CFC-12 is an important tracer for intermediately old water masses.

\subsubsection{Western Mediterranean Sea}

The CFC-12 and tritium section from the Tyrrhenian Sea through the western basin into the Alboran Sea show, that the western Mediterranean deep water (WMDW) is completely intruded by recently ventilated water masses coming from the extensive deep water formation during 20042006 (Figs. 6, 9) (Schroeder et al., 2008, 2010). The CFC-12
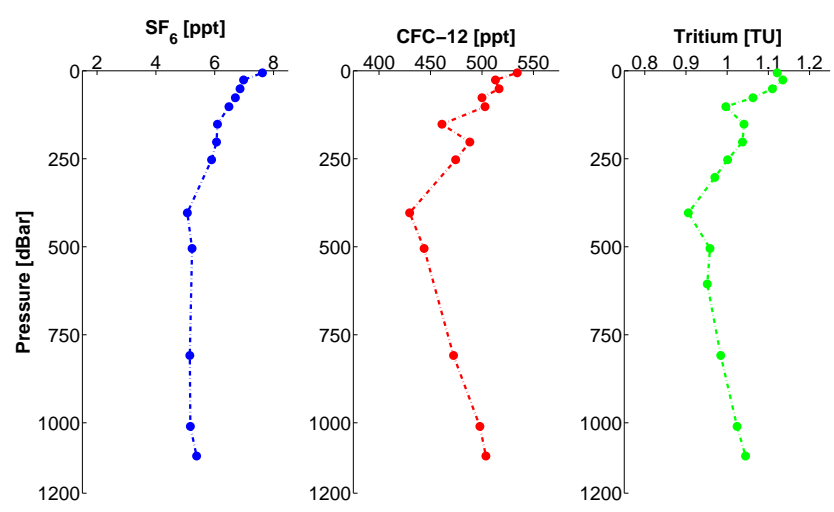

(a)
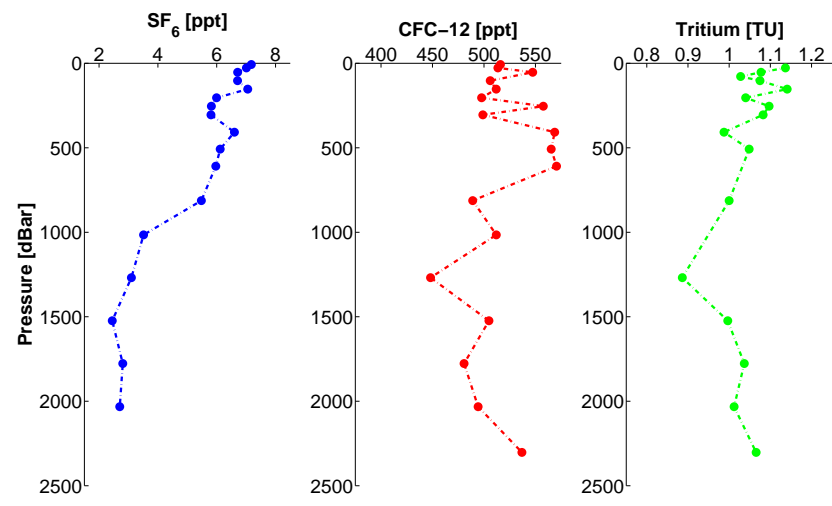

(b)

Figure 8. Profiles of transient tracers (a) in the Adriatic Sea at station 313 and (b) in the Sea of Crete at station 288 during April 2011. All three transient tracer show high concentrations throughout the entire water column of the Adriatic Sea. The Sea of Crete profiles show a clear concentration gradient for $\mathrm{SF}_{6}$, whereas the CFC-12 and tritium concentrations scatter around their maximum values.

concentrations are $>260 \mathrm{ppt}$ (Fig. 9a) and the tritium concentrations are $>0.5 \mathrm{TU}$ (Fig. 9b) throughout the entire bottom layer of the western basin reaching the channel between Sardinia and Sicily. Figure 10 shows in detail that newly formed WMDW starts to enter the Tyrrhenian Sea along this bottom contour without reaching the interior water masses in 2011. The Tyrrhenian Sea is characterized by CFC- 12 concentrations below $180 \mathrm{ppt}$ and tritium concentrations $<0.5 \mathrm{TU}$ suggesting that this basin was not affected by input of the 2004-2006 deep water formation into the deep and bottom water layers by 2011 . These relatively low tracer concentrations from the Tyrrhenian Basin rudimentary extends as tongue into the intermediate layer between 700 and $1300 \mathrm{~m}$ of the western basin which correlates with the results of Rhein et al. (1999). 


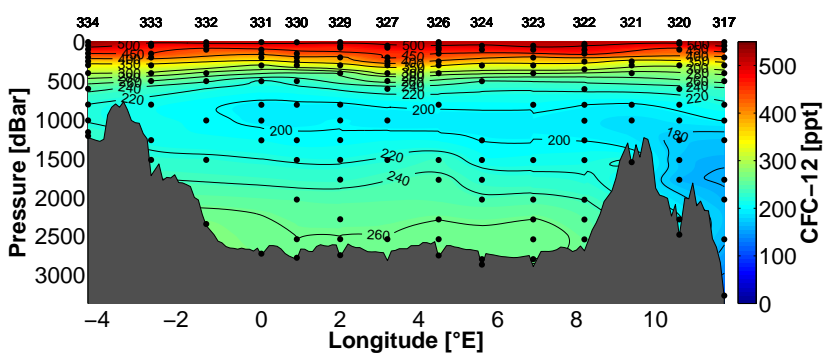

(a)

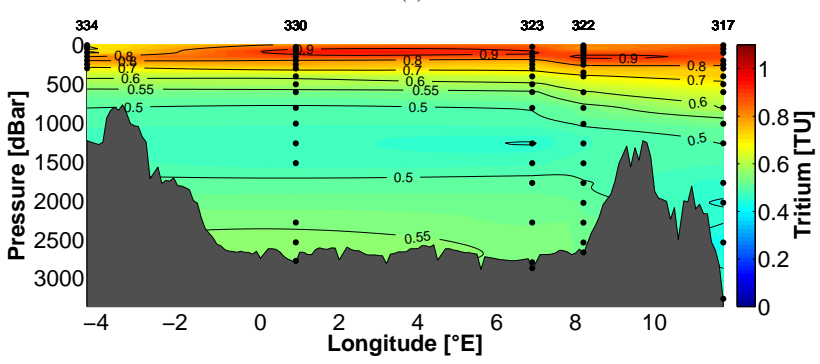

(b)

Figure 9. (a) CFC-12 concentration in ppt and (b) Tritium concentration in TU of the western basin and the Tyrrhenian Sea, blue line in Fig. 6.

\subsection{Transit time distributions}

\subsubsection{IG-TTD}

The first approach of a mean age is based on the obtained $\Delta / \Gamma$ ratios for the IG-TTD model which also provide further information on water-mass characteristics. The major share of $\Delta / \Gamma$ ratios was determinable for the $\mathrm{CFC}-12 / \mathrm{SF}_{6}$ tracer couple in a reasonable range for samples of the EMed. Figure 11a shows the section of $\Delta / \Gamma$ ratios as interpolated macrostructure in the EMed based on CFC-12 and $\mathrm{SF}_{6}$ and the IG-TTD model. The sectional interpolation quality is reduced due to few constrainable data points. Figure 11a indicates that the TMZ spreading is more affected by the EMT event than the tracer concentrations suggest. The water below $1200 \mathrm{~m}$ in the Levantine Basin has $\Delta / \Gamma$ ratios between 0.4 and 0.6 indicating a high advective behavior of the EMT event. The TMZ has ratios between 1 and 1.3 as expected for a stable water mass where diffusion predominates. The low $\Delta / \Gamma$ ratios of the EMT water masses are also observed in the easterly deep waters of the Ionian Sea, whereas the deep waters further west formed by ASOW have ratios between 1.2 and 1.4. Combining the second tracer couple consisting of $\mathrm{SF}_{6}$ and tritium yields a similar trend of $\Delta / \Gamma$ ratios in the EMed (Fig. 11b). However, there are only four stations with tritium measurements available within the section of the EMed $(290,292,301,305)$ and thus the sectional interpolation is restricted to 34 data points which does not allow a resolution of local phenomena but only provides a rough overview.

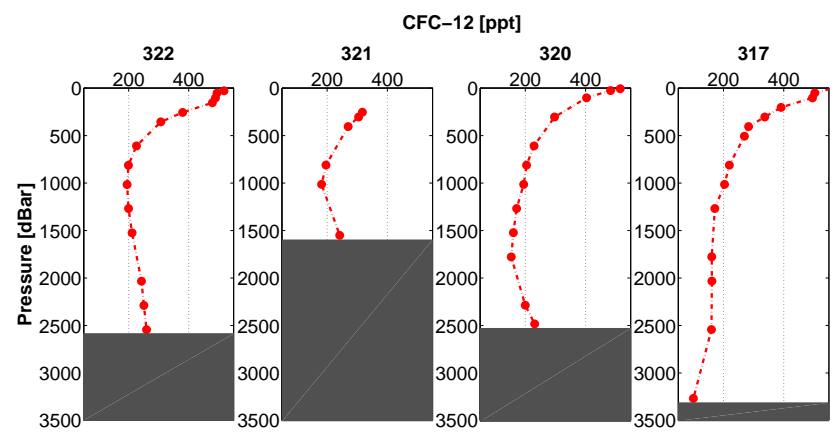

Figure 10. CFC-12 concentration in ppt along the shallow sill between Sardinia and Sicily. The elevated CFC-12 concentration of the bottom layer indicates the overflow of WMDW into the Tyrrhenian Sea. The depth of each station is indicated by the gray patch in each panel.

Comparing the $\Delta / \Gamma$ ratios in the intermediate and deep water layers of the Sea of Crete (Fig. 12a) with the EMT water masses in the Ionian and Levantine seas (Fig. 11a), one can see that the formation of the Cretan Sea overflow water (CSOW) as well as the EMT event itself were based on distinctly advective processes with an expected mean age approaching the tracer age. In contrast, water masses coming from Adriatic deep water (AdDW) seems to be formed by water masses with a more dispersive character belonging to slower formed water layers indicated by significant high $\Delta / \Gamma$ ratios between 1.1 and 1.6 (Fig. $12 \mathrm{~b}$ ). The red dots in Fig. $12 \mathrm{~b}$ indicate non-constrained data points. It can be supposed that the formation of ASOW is based on slower dispersive processes of different water masses. The westerly bottom water of the Ionian Sea show the same dispersive characteristics as the ASOW (Fig. 11a). This indicates that both states of $\Delta / \Gamma$ ratios were mainly defined by the formation process of ASOW-CSOW source water and only in minor share by mixing processes along the current pathway from source region into the interior of the Levantine and Ionian seas. Therefore, the transient tracer concentrations of both deep water masses are not necessarily simply indicators of their ventilation.

Figure 13 show the determined mean age constrained by either CFC-12 and $\mathrm{SF}_{6}$ or tritium and $\mathrm{SF}_{6}$. The tritium-/SF $6^{-}$ based maximum mean age of the TMZ in the Levantine Sea is 260 years and the deep and bottom water have a mean age between 70 and 80 years. In contrast, the $\mathrm{CFC}-12 / \mathrm{SF}_{6}$ based maximum mean age of the TMZ is 230 years with a further high mean age in the Ionian Sea between 120 and 180 years. The deep and bottom water from the EMT event is the youngest water with a mean age between 50 and 80 years reaching up to the intermediate layers at station 290 which is near the overflow area of the CSOW. Table 3 shows the mean age related to the results by Schneider et al. (2014) which were obtained by using the standard $\Delta / \Gamma$ ratio of 1.0. The comparison shows clearly the significant influence 


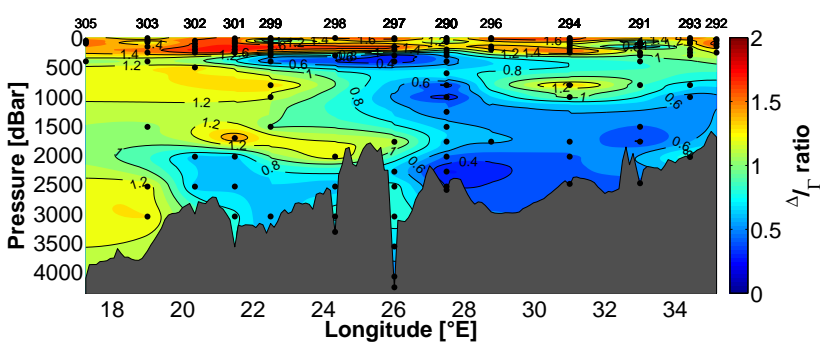

(a)

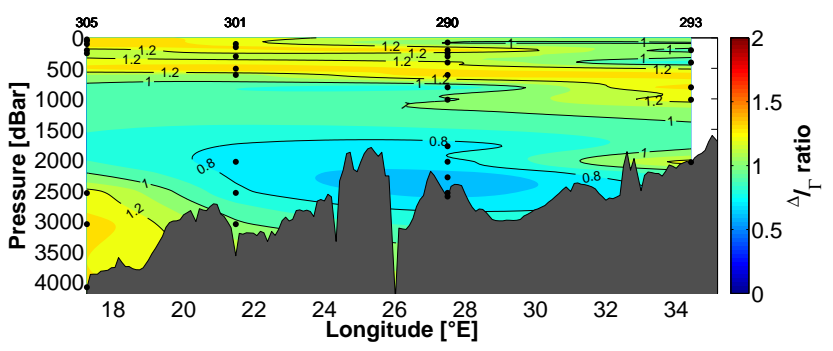

(b)

Figure 11. Determined $\Delta / \Gamma$ ratios in the EMed based on (a) the transient tracer couple CFC-12 and $\mathrm{SF}_{6}$ and (b) tritium and $\mathrm{SF}_{6}$. The black points indicate the constrained data points of the section.

of the $\Delta / \Gamma$ ratio leading to a mean age difference between both TTD approaches of almost 80 years at $800 \mathrm{~m}$ depth in the TMZ. It should be pointed out that the TTD method presented by Schneider et al. (2014) was used in another context (i.e., the analysis of a time series), with the aim of detecting temporal variations of ventilation.

The deep water in the Ionian Basin has a mean age of 100 years which underlines the difference of both deep water formations. Although the Adriatic deep water formation is contemporary and the EMT event replenished large parts of the deep waters in the early 1990s, the deep water layer formed by water masses from the Sea of Crete is much younger than the one from the Adriatic Sea. The mean age of both source regions is quite young with a maximum mean age in the deep water of $\approx 20$ years in the Aegean Sea (Fig. 14a), which highly correlates with the timing of the EMT event in the early 1990 s, and $\approx 10-17$ years in the Adriatic Sea (Fig. 14b). The mean age gradient with depth is much steeper in the Adriatic Sea than in the Sea of Crete which also shows that the ventilation processes of both basins are significantly different. However, the $\mathrm{SF}_{6}$ mean age indicated by red dots in Fig. 14b at station 313 in the Adriatic Sea fit into the mean age gradient, even though these results are based on minimum functions with a difference of more than 5 years. Such data points are defined as non-constrained, due to the uncertainty by using different transient tracers with the same "approached" constraints (even if there are a number of possible true solutions for one transient tracer). Figure 15 shows the mean age functions of CFC-12 and $\mathrm{SF}_{6}$ including the analytical error range of $4 \%$. Figure $15 \mathrm{a}$ shows an example
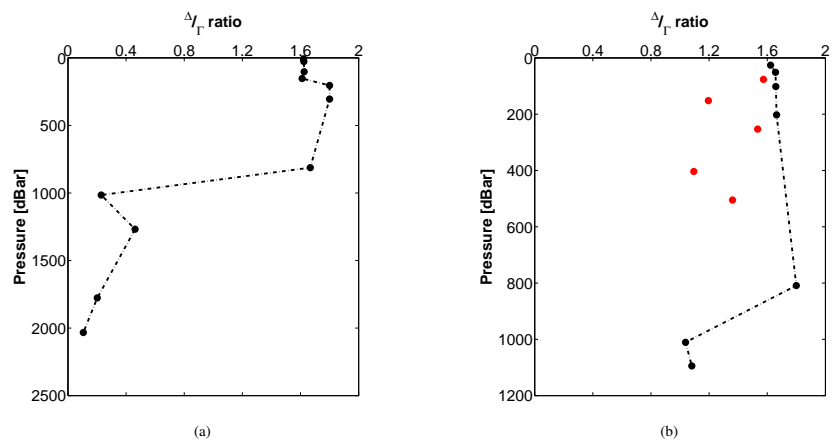

Figure 12. Determined $\Delta / \Gamma$ ratios (a) in the Sea of Crete at station 288 and (b) in the Adriatic Sea at station 313 obtained by the transient tracer couple CFC-12 and $\mathrm{SF}_{6}$. The red dots in (b) indicate ratios with a mean age difference $>5$ years and thus defined as non-constrained within the IG-TTD model.

of the CDW and Fig. 15b of the ASDW. Both plots show the differences in water-mass structure, in terms of advective/diffusive ratios, despite uncertainties in the mean age calculations.

Neglecting any systematic errors in sampling and measurements, the TTD mean age is strongly influenced by the input function of a transient tracer (see Sect. 2.4.3). The TIF by Dreisigacker and Roether (1978) and Roether et al. (1992) is a rough estimate of the complex regional impact factors and provides a mean input of tritium into the surface layer of the ocean. Nevertheless, this input function is the best existing approach and the results of the offset corrected input function clearly show that the shape of the curve tends to be correct. The corrected input function of the EMed generates similar but still a slightly higher mean age results compared to the ones obtained by $\mathrm{CFC}-12$ and $\mathrm{SF}_{6}$ (Fig. 13). This indicates that the corrected input function probably still overestimates the mean input of tritium in the eastern Mediterranean Sea. The IG-TTD provides significant results for the EMed using the tracer couple of CFC-12 and $\mathrm{SF}_{6}$, whereas $\mathrm{SF}_{6}$ and tritium should be used with some caution.

The analysis of $\Delta / \Gamma$ ratios in the WMed is restricted to only three stations $(317,323,334)$ for which the concentration ratios between the two transient tracer couples were not applicable to the IG-TTD model. The simple approach of water-mass analysis concerning the advective/diffusive ratio and the calculation of a mean age is not possible. Another distribution model is needed to estimate a mean age of nonconstrainable data points of both tracer couples in the western Mediterranean Sea.

In this context, it is useful to determine the validity area of a tracer couple, to decide whether the IG or 2IG-TTD model should be applied. Figure 16 shows the validity area of the IG- and 2IG-TTD models by using the tracer age differences of $\mathrm{SF}_{6}$ and $\mathrm{CFC}-12$ in the EMed. The young and advective EMT water mass can be described by the IG-TTD, whereas the mean age of the intermediate water and parts of the deep 
Table 3. Comparison of mean age results between a TTD model with constrained $\Delta / \Gamma$ ratios and a TTD model with standard ratio $\Delta / \Gamma=$ 1.0 (Schneider et al., 2014).

\begin{tabular}{rrrrrrr}
\hline & \multicolumn{2}{c}{ Constrained ratios } & & \multicolumn{2}{c}{ Standard ratio } & \\
\cline { 2 - 3 } Pressure [dBar] & Mean age [yr] & $\Delta / \Gamma$ ratio & & Mean age [yr] & $\Delta / \Gamma$ ratio & Difference [yr] \\
\hline 200 & 27 & 0.80 & & 29 & 1.0 & 2 \\
250 & 30 & 0.63 & & 38 & 1.0 & 8 \\
300 & 38 & 0.71 & & 47 & 1.0 & 9 \\
400 & 47 & 0.61 & & 69 & 1.0 & 22 \\
600 & 83 & 0.76 & & 105 & 1.0 & 22 \\
800 & 44 & 0.21 & & 123 & 1.0 & 79 \\
1000 & 43 & 0.21 & & 120 & 1.0 & 77 \\
1250 & 57 & 0.47 & & 105 & 1.0 & 48 \\
1500 & 67 & 0.63 & & 115 & 1.0 & 48 \\
1750 & 77 & 0.59 & & 135 & 1.0 & 58 \\
2000 & 48 & 0.43 & & 99 & 1.0 & 51 \\
2250 & 41 & 0.19 & & 99 & 1.0 & 58 \\
2500 & 41 & 0.25 & & 80 & 1.0 & 39 \\
2600 & 52 & 0.53 & & 94 & 1.0 & 42 \\
\hline
\end{tabular}

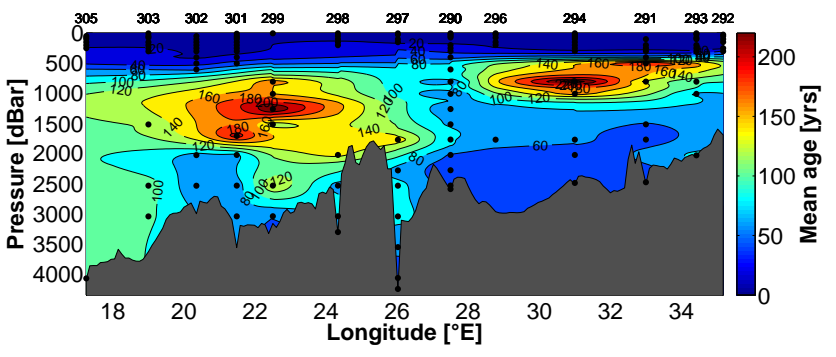

(a)

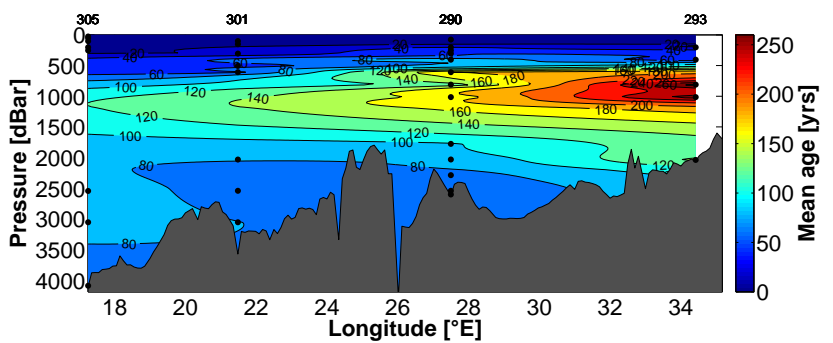

(b)

Figure 13. Mean age of the EMed based on an IG-TTD constrained by (a) the transient tracer couple $\mathrm{CFC}-12$ and $\mathrm{SF}_{6}$ and (b) tritium and $\mathrm{SF}_{6}$.

water in the EMed as well as the complete WMed might be better evaluated by a 2IG-TTD. The limiting difference also depends on the tracer concentration to some extend, so that the mixed layer and parts of the pycnocline can also be described by the IG model, although the tracer age difference is larger than 10 years. Development of a clear mathematical definition of validity areas of different tracer couples and distribution models will be part of future work.
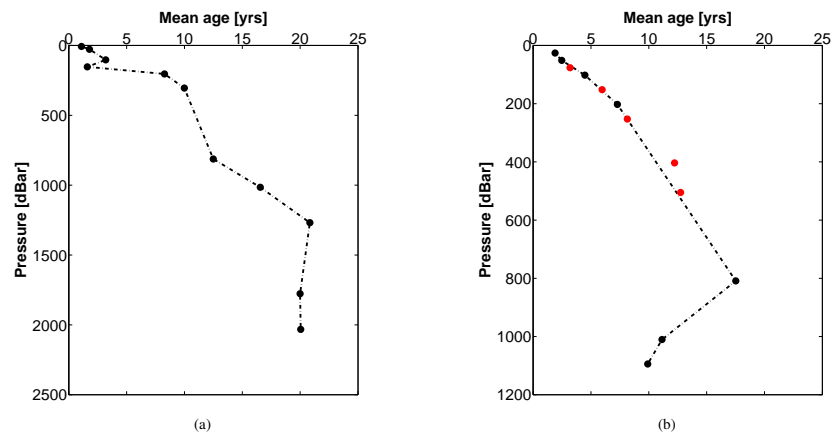

Figure 14. Determined mean age (a) in the Sea of Crete at station 288 and (b) in the Adriatic Sea at station 313 based on $\mathrm{SF}_{6}$ and an IG-TTD constrained by the transient tracer couple CFC-12 and $\mathrm{SF}_{6}$. The red dots show $\mathrm{SF}_{6}$ mean age results with a difference of more than 5 years compared to the $\mathrm{CFC}-12$ mean age (i.e., nonconstrained mean age).

\subsubsection{IG-TTD}

The predefined 2IG-TTD was applied to several key stations in the EMed and WMed $(290,305,317,323)$ shown in Fig. 6. As mentioned above we assumed fixed $\Delta / \Gamma$ ratios for both TTDs so that $\Delta_{1} / \Gamma_{1}=1.4$ and $\Delta_{2} / \Gamma_{2}=0.6$, respectively and that the mean age $\Gamma_{2}<\Gamma_{1}$ under the assumption that $\Gamma_{2}$ describes the younger water parcel. The concentration curve (Fig. 4) of each transient tracer were combined in one matrix to determine the intersections. The weighting factor $\alpha$ was separated in $10 \%$ steps and thus we yielded eleven concentration matrices for each sample point. The determination of the intersections was carried out numerically to obtain a first overview of possible 2IG-TTD results which are shown in Table 4, where the mean age is based on the concentrations 
Table 4. Suggested mean age based on a 2IG-TTD at (a) station 290, (b) station 305, (c) station 317 and (d) station 323, where n.c. stands for non-constrained data points. The most prominent water layers are labeled according to the OMP of Hainbucher et al. (2013) including modified Atlantic water (MAW), Levantine surface water (LSW), Levantine intermediate water (LIW), eastern Mediterranean deep water (EMDW), western Mediterranean deep water (WMDW), Tyrrhenian deep water (TDW) and Adriatic deep water (AdDW).

\begin{tabular}{|c|c|c|c|c|c|c|}
\hline (a) & Pressure [dBar] & $\alpha[\%]$ & $\Gamma_{1}[\mathrm{yr}]$ & $\Gamma_{2}[\mathrm{yr}]$ & Mean age [yr] & Water layer \\
\hline & 51 & 0 & 0 & 12 & 12 & LSW \\
\hline & 75 & 0 & 0 & 15 & 15 & transition \\
\hline & 202 & 0 & 0 & 25 & 25 & LIW \\
\hline & 254 & 0 & 0 & 30 & 30 & LIW \\
\hline & 304 & 0 & 0 & 38 & 38 & LIW \\
\hline & 404 & 0 & 0 & 46 & 46 & transition \\
\hline & 607 & 0 & 0 & 60 & 60 & transition \\
\hline & 810 & n.c. & n.c. & n.c. & n.c. & transition \\
\hline & 1013 & n.c. & n.c. & n.c. & n.c. & EMDW \\
\hline & 1267 & n.c. & n.c. & n.c. & n.c. & EMDW \\
\hline & 1522 & 0 & 0 & 67 & 67 & EMDW \\
\hline & 1775 & 0 & 0 & 77 & 77 & EMDW \\
\hline & 2031 & n.c. & n.c. & n.c. & n.c. & EMDW \\
\hline & 2286 & n.c. & n.c. & n.c. & n.c. & EMDW \\
\hline & 2540 & n.c. & n.c. & n.c. & n.c. & EMDW \\
\hline & 2600 & 0 & 0 & 60 & 60 & EMDW \\
\hline \multirow[t]{18}{*}{ (b) } & Pressure [dBar] & $\alpha[\%]$ & $\Gamma_{1}[\mathrm{yr}]$ & $\Gamma_{2}[\mathrm{yr}]$ & Mean age [yr] & Water layer \\
\hline & 26 & n.c. & n.c. & n.c. & n.c. & MAW \\
\hline & 52 & n.c. & n.c. & n.c. & n.c. & MAW \\
\hline & 77 & n.c. & n.c. & n.c. & n.c. & transition \\
\hline & 102 & 10 & 59 & 1 & 7 & transition \\
\hline & 152 & 40 & 23 & 1 & 10 & LIW \\
\hline & 203 & 50 & 28 & 1 & 15 & LIW \\
\hline & 254 & 60 & 33 & 2 & 20 & LIW \\
\hline & 304 & 50 & 63 & 2 & 33 & LIW \\
\hline & 405 & 60 & 81 & 2 & 50 & transition \\
\hline & 506 & 70 & 125 & 2 & 88 & transition \\
\hline & 608 & 70 & 207 & 7 & 147 & transition \\
\hline & 1013 & 80 & 320 & 8 & 258 & AdDW \\
\hline & 1522 & 80 & 246 & 5 & 197 & AdDW \\
\hline & 2032 & 70 & 279 & 4 & 196 & AdDW \\
\hline & 2543 & 90 & 138 & 7 & 125 & AdDW \\
\hline & 3053 & 80 & 167 & 6 & 134 & AdDW \\
\hline & 4087 & 90 & 101 & 4 & 91 & AdDW \\
\hline
\end{tabular}

of $\mathrm{CFC}-12, \mathrm{SF}_{6}$ and to some extent also tritium (see discussion below).

Station 290 in the Levantine Sea can be perfectly described by the IG-TTD which is also indicated by the 2IG-TTD results. As shown in Table 4 the best fits for all samples were obtained for $\alpha=0$ which is the lower limiting case where the 2IG-TTD turns into an IG-TTD with $\Gamma=\Gamma_{2}$. Hence, the mean age of the 2IG-TTD is the same as the one from the constrained IG-TTD where $\Delta / \Gamma=0.6$. The missing data in Table 4 corresponds to the mean age of IG-TTDs with $\Delta / \Gamma$ ratios $<0.6$. Figure 17 shows the characteristics of such a concentration curve plot. For $\alpha=0$, the lines of CFC-12 and $\mathrm{SF}_{6}$ are overlapping, whereas the one of tritium is slightly above, again indicating a higher mean age by this tracer. The sensitivity of changes with increasing $\alpha$ is of different extend for each tracer. The rate of change is highest for tritium, followed by CFC-12 and lowest for $\mathrm{SF}_{6}$. This results in curve intersections when $\Gamma_{2}$ (Tritium) $>\Gamma_{2}($ CFC-12) $>$ $\Gamma_{2}\left(\mathrm{SF}_{6}\right)$ at $\alpha=0$.

Such condition can be found at station 305 , which is a key station in the Ionian Sea where the IG-TTD is less constrained in the intermediate and deep water. However, CFC12 and $\mathrm{SF}_{6}$ intersect each other for several values of alpha, so we chose the one with the lowest difference to the tritium intersection (Fig. 18). Table 4 shows the results of the 2IG-TTD for station 305. The intermediate and deep water is characterized by high $\alpha$ values between 80 and $90 \%$, indicating a stronger influence of more stationary water masses. 
Table 4. Continued.

\begin{tabular}{rrrrrll}
\hline (c) & Pressure [dBar] & $\alpha[\%]$ & $\Gamma_{1}[\mathrm{yr}]$ & $\Gamma_{2}[\mathrm{yr}]$ & Mean age [yr] & Water layer \\
\hline 51 & n.c. & n.c. & n.c. & n.c. & MAW \\
102 & n.c. & n.c. & n.c. & n.c. & transition \\
203 & n.c. & n.c. & n.c. & n.c. & LIW \\
304 & n.c. & n.c. & n.c. & n.c. & LIW \\
405 & n.c. & n.c. & n.c. & n.c. & LIW \\
507 & n.c. & n.c. & n.c. & n.c. & LIW \\
811 & n.c. & n.c. & n.c. & n.c. & transition \\
1014 & n.c. & n.c. & n.c. & n.c. & TDW \\
1267 & 70 & 757 & 3 & 531 & TDW \\
1776 & 80 & 370 & 6 & 297 & TDW \\
2032 & 90 & 230 & 18 & 208 & TDW \\
2542 & 90 & 246 & 4 & 221 & TDW \\
3268 & n.c. & n.c. & n.c. & n.c. & TDW \\
\hline Pressure $[\mathrm{dBar}]$ & $\alpha[\%]$ & $\Gamma_{1}[\mathrm{yr}]$ & $\Gamma_{2}[\mathrm{yr}]$ & Mean age $[\mathrm{yr}]$ & Water layer \\
\hline 52 & n.c. & n.c. & n.c. & n.c. & MAW \\
103 & n.c. & n.c. & n.c. & n.c. & transition \\
203 & 50 & 127 & 2 & 64 & transition \\
304 & 60 & 135 & 2 & 82 & LIW \\
406 & 70 & 170 & 3 & 120 & LIW \\
812 & 80 & 228 & 8 & 184 & transition \\
1523 & 80 & 222 & 4 & 178 & WMDW \\
2031 & 60 & 411 & 4 & 248 & WMDW \\
2287 & 60 & 332 & 1 & 200 & WMDW \\
2542 & 60 & 294 & 3 & 177 & WMDW \\
2798 & 60 & 364 & 2 & 219 & WMDW \\
\hline (d) & & & & &
\end{tabular}

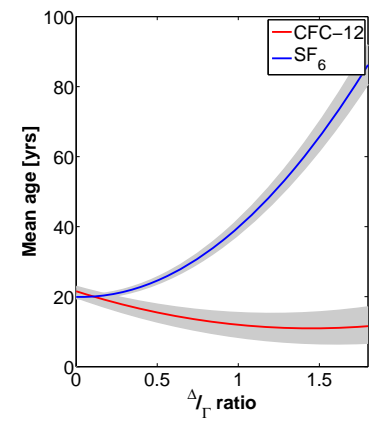

(a)

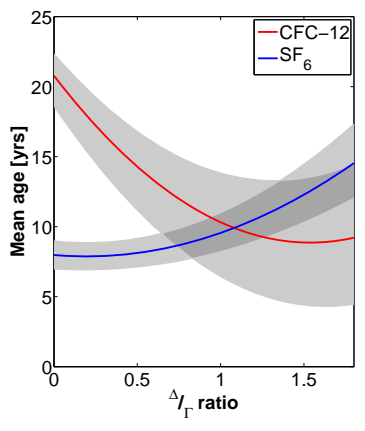

(b)
Figure 15. Mean age functions of CFC-12 and $\mathrm{SF}_{6}$ at station 288 , (a) in the Sea of Crete at $2030 \mathrm{~m}$ depth and (b) at station 313 in the Adriatic Sea at $1094 \mathrm{~m}$ depth with an error range of $4 \%$ analytical error.

Looking at the single mean age results of the distribution, the total mean age is mainly influenced by $\Gamma_{1}$ rather than $\Gamma_{2}$, whereas both single results are not significant for statements about real mixing processes. They are rather part of the predefined model characteristics and provide only tendencies of the water-mass behavior. Whereas the total mean age from the constrained and exact determined TTD model describes the solved equation and thus a significant mean age result of

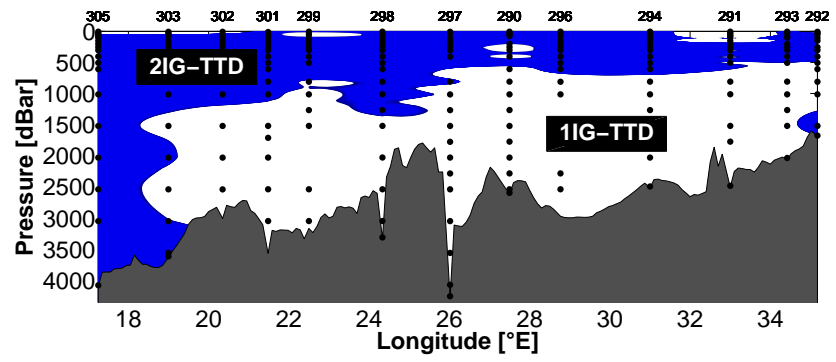

Figure 16. Differences of the tracer age between CFC-12 and $\mathrm{SF}_{6}$. The white shading describes tracer age differences below and the blue shading above 10 years.

a water parcel. The highest mean age of 260 years can be found at $\approx 1000 \mathrm{~m}$ depth, whereas the mean age decreases to 90 years at the bottom layer. This is in full compliance with the expected younger water masses belonging to the ASOW. Compared to the IG-TTD, which indicates a mean age of 100 years for most of the water column, the 2IG-TTD shows a more differentiated structure with a clear mean age maximum. This case indicates that the 2IG-TTD provides more reasonable results.

The order of the tracer mean age at station 317 in the Tyrrhenian Sea changes from the required standard condition 

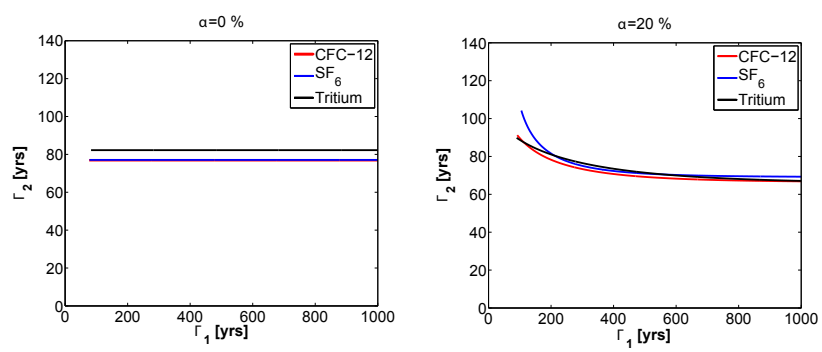

(a)

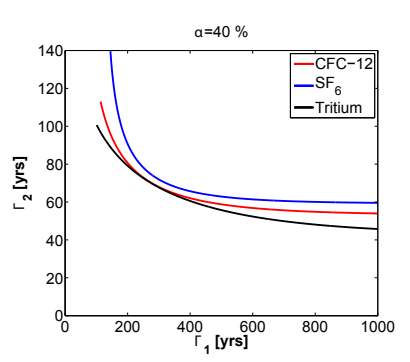

(c)

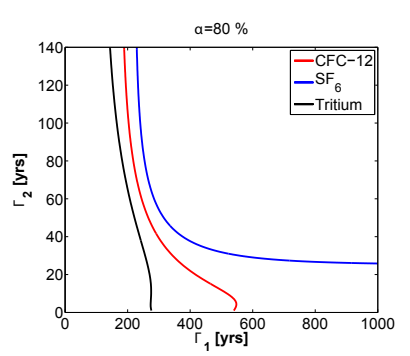

(e)

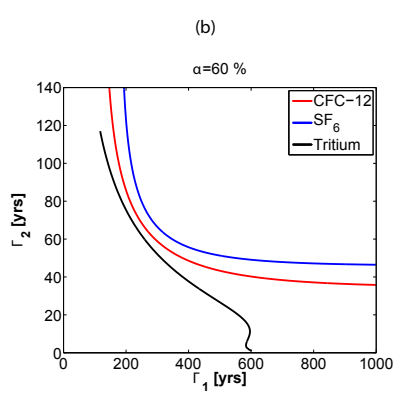

(d)

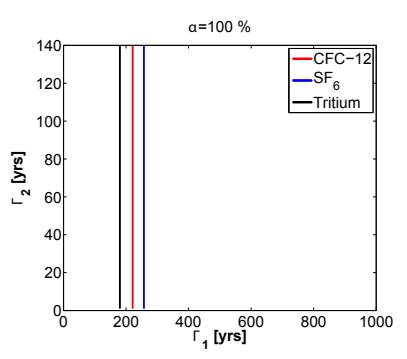

(f)

Figure 17. Example of a mean age calculation from three transient tracers (CFC-12, $\mathrm{SF}_{6}$ and tritium) at station 290 at $1775 \mathrm{~m}$ depth. The six panels are for different fractions of the older water mass $(\alpha$ value). The $\Delta / \Gamma$ ratios are set to 0.6 for the younger water mass, and to 1.4 for the older water mass. Panel (a) shows the selected result, see text.

into $\Gamma_{2}(\mathrm{CFC}-12)>\Gamma_{2}($ Tritium $)>\Gamma_{2}\left(\mathrm{SF}_{6}\right)$ for depths shallower than $1250 \mathrm{~m}$. This change in order is also the limit of the used model, so that only four samples could be determined in the Tyrrhenian Sea (Table 4). The mean age is $\approx 200$ years in the deep water and increase up to 531 years at $1250 \mathrm{~m}$. The Tyrrhenian Sea is less affected by intrusion of younger water masses and thus one would expect this high mean age in this basin. There might be several reasons why the major part of the mean age is not determinable in the Tyrrhenian Sea. The values for $\Gamma_{1}$ are increasing with decreasing depth up to 757 years. The used mean age matrices have a size of $1000 \times 200$, so that a maximum mean age of 1000 years can be determined for $\Gamma_{1}$. The shape of the curves of CFC-12 and $\mathrm{SF}_{6}$ show the tendency to have intersections beyond this limit and thus a much higher mean age for $\Gamma_{1}$ than 1000 years. Another possible reason might be the assumed values of $\Delta / \Gamma$ ratios of the 2IG-TTD.
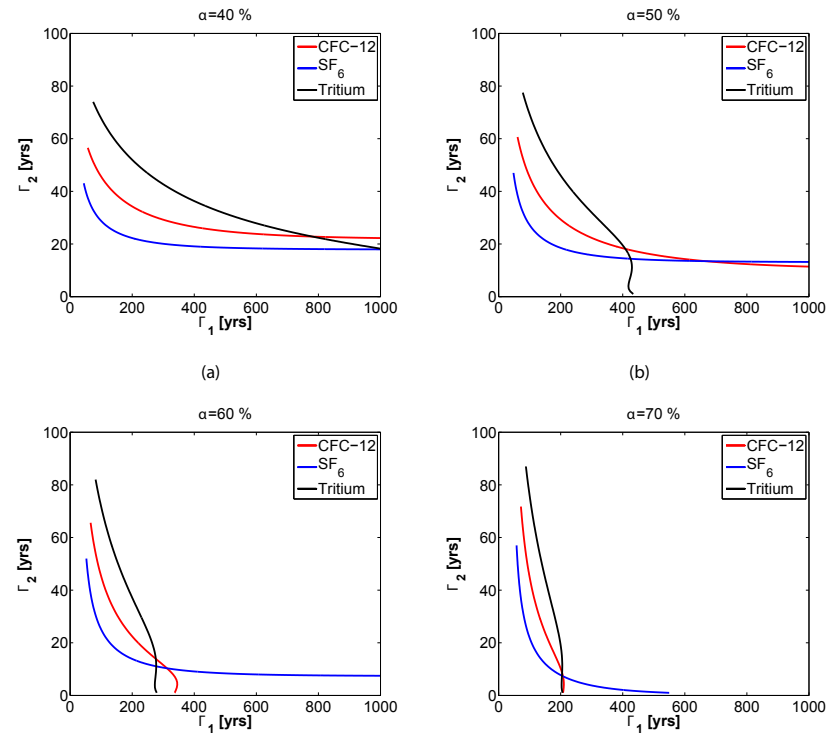

(c)

(d)

Figure 18. Example for a mean age calculation from three transient tracers (CFC-12, $\mathrm{SF}_{6}$ and tritium) at station 305 at $608 \mathrm{~m}$ depth. Panel (d) shows a triple intersection of all three transient tracer concentrations $(\alpha=70 \%)$ and thus a solution for the mean age at this data point of 147 years.

Station 323 in the Algero-Provençal Basin shows significant characteristics of the newly formed deep and bottom water layer with a constant $\alpha$ of $60 \%$ and a mean age between 170 and 250 years (Table 4, Fig. 19). The lower values of $\alpha$ besides a relatively high mean age describe the extensive intrusion of young water masses into an old deep water layer. The interbasin circulation pattern between the AlgeroProvençial Basin and the Tyrrhenian Sea is characterized by high $\alpha$ values denoting less influence of advective water mass input at depth between 1500 and $800 \mathrm{~m}$. However, the mean age is relatively low at this depth range at station 323. Even though the massive inflow of recently ventilated water of 2004-2006 might have notably lowered the mean age, the oldest water masses can be still found in the deep and bottom water. So it can be suggested that these water layers of the western basin were probably less mixed over decadal to centennial timescales. The IG-TTD and tracer age concepts both indicates the oldest waters at intermediate depths (e.g., Rhein et al., 1999; Schneider et al., 2014), whereas our analysis show the highest mean age values in the deep water. This illustrates the power of the 2IG-TTD approach.

\subsection{Best mean age approach}

The combination of both TTD models allows for an exchange of non-constrainable data points within the IG-TTD by constrained data points of the predefined 2IG-TTD, so that in total $96 \%$ of the data points in the EMed and $81 \%$ in the WMed could be constrained (Table 5). This 


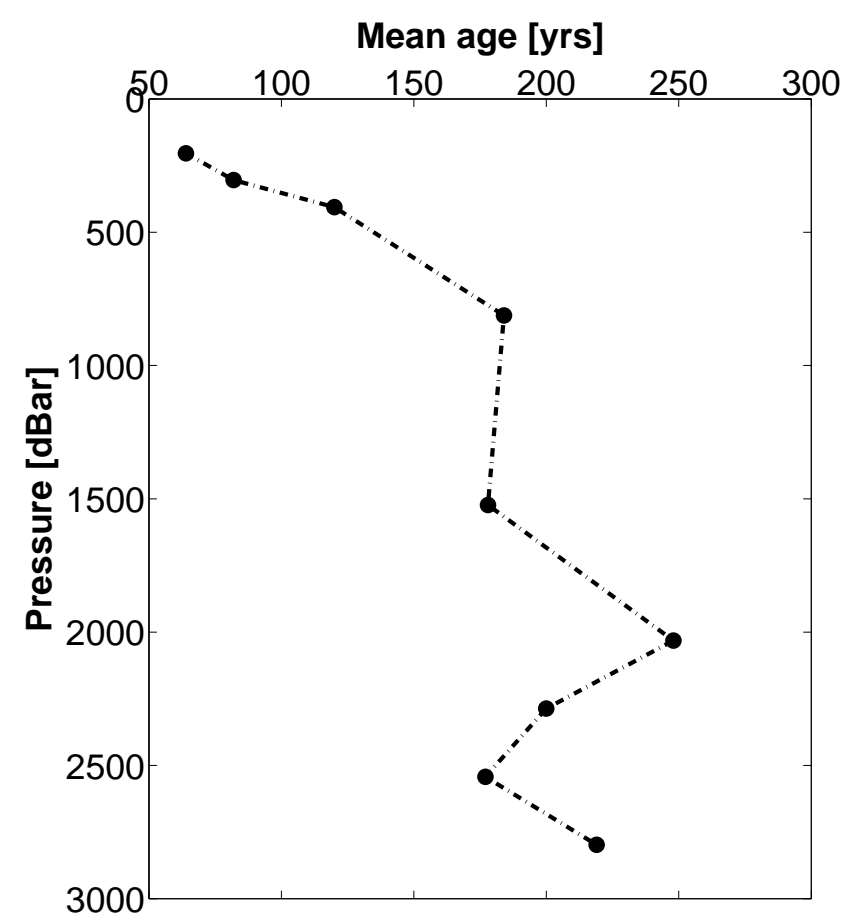

Figure 19. Mean age at station 323 in the WMed based on a 2IGTTD constrained by the transient tracer couple CFC-12 and $\mathrm{SF}_{6}$.

Table 5. Number of constrained data points of the IG- and 2IG-TTD using $\mathrm{SF}_{6}, \mathrm{CFC}-12$ and Tritium.

\begin{tabular}{llrrr}
\hline Tracer couple & & Data points & IG & 2IG \\
\hline \multirow{3}{*}{$\mathrm{CFC} 12 / \mathrm{SF}_{6}$} & Total & 412 & 230 & 301 \\
& WMed & 38 & 14 & 23 \\
& EMed & 375 & 216 & 278 \\
\hline \multirow{3}{*}{${ }^{3} \mathrm{H}^{\mathrm{S} \mathrm{SF}_{6}}$} & Total & 206 & 71 & - \\
& WMed & 86 & 17 & - \\
& EMed & 120 & 54 & - \\
\hline
\end{tabular}

cross-interlocking of both models provides the best estimate of the mean age in the eastern part of the Mediterranean Sea (Fig. 20). The young water masses of the EMT event can be clearly seen in the deep and bottom layers of the Levantine and Ionian Basin with a mean age between 60 and 80 years as well as the newly formed deep water in the westerly parts of the Ionian Basin with a mean age between 120 and 160 years. The mean age maximum layer extends from 600 to $2000 \mathrm{~m}$ depth throughout the entire EMed with a mean age between 160 and 290 years. The maximum mean age of 290 years can be found in the TMZ in the Levantine Sea. This high mean age layer is disrupted by a lower mean age of $\approx 140$ years at the outflow areas of the Sea of Crete (station 299 and 290) and the area near Rhodes (station 293).

\section{Conclusions}

We have described a comprehensive data set of transient tracer concentrations obtained during the Meteor $84 / 3$ cruise in the Mediterranean Sea in April 2011. For the first time measurements of $\mathrm{SF}_{6}, \mathrm{CFC}-12$, tritium and ${ }^{3} \mathrm{He}$ were performed simultaneous on a cruise covering all major basins of the Mediterranean Sea. With this data set, we constrain ventilation characteristics using the transit time distribution (TTD) framework. In particular we constrain the TTD assuming inverse Gaussian (IG) shape of the TTD, either as a one-modal (IG) or two-modal (2IG) distribution. The shapedetermining parameters of the IG distribution are the width $(\Delta)$ and mean age $(\Gamma)$, the relative contribution of the two water masses of a 2IG distribution $(\alpha)$, as well as the ratio of $\Delta / \Gamma$ that is indicative of the diffusive to advective transport characteristic of a water mass.

Most regions of the EMed can be described by the IGTTD model but with widely different $\Delta / \Gamma$ characteristic of the two main deep-water sources, the Cretan deep water (CDW) and the Adriatic Sea overflow water (ASOW), which have developed their $\Delta / \Gamma$ ratio already at their origin region rather than along the flow pathway. The Aegean Sea source water shows a more advective (i.e., a low $\Delta / \Gamma$ ratio) behavior than the Adriatic Sea source water. The majority of the deep water in the eastern Mediterranean of Aegean source originates from the Eastern Mediterranean Transient (EMT) event in the early 1990s. The unusually high deep-water formation rates during this event might explain the advective characteristics of this water mass, which had a mean age between 50 and 80 years. The mean age of the EMT-induced water masses in the Levantine Basin is thus still younger than the deep water in the deep Ionian Sea that has a mean age of approximately 120-160 years using the 2IG-TD model. This is, at first sight, counterintuitive considering the higher CFC-12 concentration in the deep Ionian Sea due to recent contribution from the deep water source in the Adriatic Sea. All tracers show a distinct minimum at around $1000 \mathrm{~m}$ depth throughout the Med, although the origin of this tracer minimum zone (TMZ) is slightly different for the eastern and western basins. For the EMed horizontal gradients in the $\Delta / \Gamma$ ratio lead to a mean age distribution that not directly correlated to the tracer concentrations, with lower a mean age southeast of Crete, in the outflow region of water from the Sea of Crete, and a higher age in the Levantine Basin and Ionian Sea.

Although most of the EMed ventilation can be described by an IG-TTD model, there are areas where this model of mixing cannot explain the observed tracer distributions. We found the IG-TTD approximation to be invalid for water samples with a tracer age difference exceeding $\approx 10$ years (for the $\mathrm{SF}_{6}$-CFC-12 couple sampled in 2011). Thus we use a 2IG model to constrain the TTD in the western part of the Ionian Sea and most of the WMed. The Western Mediterranean Transition (WMT) event with enhanced deep-water 


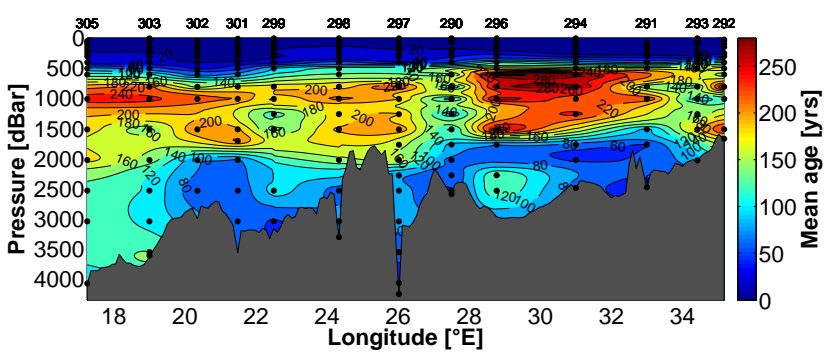

Figure 20. Best estimate of the mean age of the EMed based on the combination of an IG-TTD and a predefined 2IG-TTD constrained by the transient tracer couple CFC-12 and $\mathrm{SF}_{6}$.

formation during the winters of 2004-2006 in the western basin can be characterized by the 2IG-TTD model, where the recently ventilated deep-water with advective properties mixes with more stationary water of more diffusive character. The contemporaneous deep water in WMed has approximately $40 \%$ contribution of recently ventilated waters from the WMT, leading to a mean age of about 200 years, which is similar or higher than the mean age higher up in the water column that have lower $\mathrm{CFC}-12$ and $\mathrm{SF}_{6}$ concentrations. This highlights the need to constrain the TTD in order to understand the "age" of a water mass based on transient tracer concentrations. The recently ventilated deep water was observed as elevated concentrations of CFC-12 in excess of $200 \mathrm{ppt}$ along the bottom in the Sardinia Channel towards, but not yet within, the Tyrrhenian Sea. The horizontally relatively homogeneous CFC-12 concentration of the western basin suggest that the TTD structure determined at station 323, SW of Sardinia, can be extrapolated to large parts of the WMed.

The results presented here point to the need to consider alternatives to the commonly applied IG-TTD model, particularly in regions with variable ventilation or where more water masses mix with each other. For observational constraints of more complex TTDs, a suite of transient tracers needs to be measured and interpreted. For such regions in the ocean, we show that a predefined 2IG-TTD provides a useful tool.

Acknowledgements. The authors want to thank the captain and crew on the research vessel Meteor for the excellent cooperation during the campaign. The Meteor cruise M84/3 and the transient tracer measurements were supported by a grant from the Deutsche Forschungsgemeinschaft Senatskommission für Ozenographie (DFG), and from a grant from the DFG; TA 317/3-1. Furthermore we would like to thank Wolfgang Roether for his support, help and inspiring discussions on particular matters of helium and tritium. Our special thanks goes to Damian Grundle and Martha Gledhill for linguistic improvements of the manuscript.
The service charges for this open access publication have been covered by a Research Centre of the Helmholtz Association.

Edited by: S. Sparnocchia

\section{References}

Artegiani, A., Bregant, D., Paschini, E., Pinardi, N., Raicich, F., and Russo, A.: The Adriatic Sea General Circulation. Part I: Air-Sea Interactions and Water Mass Structure, J. Phys. Oceanogr., 27, 1492-1514, 1996a.

Artegiani, A., Bregant, D., Paschini, E., Pinardi, N., Raicich, F., and Russo, A.: The Adriatic Sea General Circulation. Part II: Baroclinic Circulation Structure, J. Phys. Oceanogr., 27, 1515-1532, $1996 b$.

Brasseur, P., Beckers, J., Brankart, J., and Schoenauen, R.: Seasonal temperature and salinity fields in the Mediterranean Sea: Climatological analyses of a historical data set, Deep Sea Res.-Pt. I, 43, 159-192, 1996.

Bullister, J. L.: Atmospheric CFC-11, CFC-12, CFC-113, $\mathrm{CCl}_{4}$ and $\mathrm{SF}_{6}$ Histories (1910-2011), Carbon Dioxide Information Analysis Center, available at: http://cdiac.ornl.gov/oceans/new_ atmCFC.html (last access: 1 June 2014), 2011.

Bullister, J. L. and Wisegarver, D.: The shipboard analysis of trace levels of sulfur hexafluoride, chlorofluorocarbon-11 and chlorofluorocarbon-12 in seawater, Deep Sea Res.-Pt. I, 55, 1063-1074, 2008.

Bullister, J., Wisegarver, D., and Menzia, F.: The solubility of sulfur hexafluoride in water and seawater, Deep Sea Res.-Pt. I, 49, 175187, 2002.

DeGrandpre, M. D., Koertzinger, A., Send, U., Wallace, D. W. R., and Bellerby, R. G. J.: Uptake and sequestration of atmospheric $\mathrm{CO}_{2}$ in the Labrador Sea deep convection region, Geophys. Res. Lett., 33, doi:10.1029/2006GL026881, 2006.

Delhez, E., de Brye, B., de Brauwere, A., and Deleersnijder, E.: Residence time vs influence time, J. Marine Syst., 132, 185-195, doi:10.1016/j.jmarsys.2013.12.005, 2013.

Dreisigacker, E. and Roether, W.: Tritium and ${ }^{90} \mathrm{Sr}$ in North Atlantic surface water, Earth Planet. Sci. Lett., 38, 301-312, 1978.

Ferronsky, V. and Polyakov, V.: Environmental isotopes in the hydrosphere, John Wiley \& Sons, Chichester, New York, 1982.

Hainbucher, D., Rubino, A., and Klein, B.: Water mass characteristics in the deep layers of the western Ionian Basin observed during May 2003, Geophys. Res. Lett., 33, L05608, doi:10.1029/2005GL025318, 2006.

Hainbucher, D., Rubino, A., Cardin, V., Tanhua, T., Schroeder, K., and Bensi, M.: Hydrographic situation during cruise M84/3 and P414 (spring 2011) in the Mediterranean Sea, Ocean Sci. Discuss., 10, 2399-2432, doi:10.5194/osd-10-2399-2013, 2013.

Haine, T. W. N. and Richards, K. J.: The influence of the seasonal mixed layer on oceanic uptake of CFCs, J. Geophys. Res.Oceans, 100, 10727-10744, doi:10.1029/95JC00629, 1995.

Hall, T. and Plumb, R.: Age as a diagnostic of stratospheric transport, J. Geophys. Res., 99, 1059-1070, 1994.

Hall, T., Haine, T., Waugh, D., Holzer, M., Terenzi, F., and LeBel, D.: Ventilation rates Estimated from Tracers in the Presence of Mixing, J. Phys. Oceanogr., 37, 2599-2611, doi:10.1175/2006JPO3471.1, 2007. 
Houghton, J., Meira Filho, L., Callander, B., Harris, N., Kattenberg, A., and Maskell, K.: Climate Change 1995, The Science of Climate Change, Cambridge University Press, 1996.

Hu, Z., Doglioli, A., Petrenko, A., Marsaleix, P., and Dekeyser, I.: Numerical simulations of eddies in the Gulf of Lion, Ocean Model., 28, 203-208, doi:10.1016/j.ocemod.2009.02.004, 2009.

Huhn, O., Rhein, M., Hoppema, M., and van Heuven, S.: Decline of deep and bottom water ventilation and slowing down of anthropogenic carbon storage in the Weddell Sea, 1984-2011, Deep Sea Res.-Pt. I, 76, 66-84, doi:10.1016/j.dsr.2013.01.005, 2013.

Klein, B., Roether, W., Manca, B., Bregant, D., Beitzel, V., Kovacevic, V., and Luchetta, A.: The large deep water transient in the Eastern Mediterranean, Deep Sea Res.-Pt. I, 46, 371-414, doi:10.1016/S0967-0637(98)00075-2, 1999.

Lascaratos, A., Williams, R., and Tragou, E.: A Mixed-Layer Study of the Formation of Levantine Intermediate Water, J. Geophys. Res., 98, 14739-14749, 1993.

Lascaratos, A., Roether, W., Nittis, K., and Klein, B.: Recent changes in deep water formation and spreading in the eastern Mediterranean Sea: a review, Prog. Oceanogr., 44, 5-36, doi:10.1016/S0079-6611(99)00019-1, 1999.

Law, C., Watson, A., and Liddicoat, M.: Automated vacuum analysis of sulphur hexafluoride in seawater: derivation of the atmospheric trend (1970-1993) and potential as a transient tracer, Mar. Chem., 48, 57-69, 1994.

Malanotte-Rizzoli, P. and Hecht, A.: Large scale properties of the eastern Mediterranean: a review, Oceanol. Acta, 11, 323-335, 1988.

Primeau, F. and Holzer, M.: The Ocean's Memory of the Atmosphere: Residence-Time and Ventilation-Rate Distribution of Water Masses, J. Phys. Oceanogr., 36, 1439-1456, doi:10.1175/JPO2919.1, 2006.

Rhein, M., Send, U., Klein, B., and Krahmann, G.: Interbasin deep water exchange in the western Mediterranean, J. Geophys. Res.Oceans, 104, 23495-23508, doi:10.1029/1999JC900162, 1999.

Roether, W. and Lupton, J. E.: Tracers confirm downward mixing of Tyrrhenian Sea upper waters associated with the Eastern Mediterranean Transient, Ocean Sci., 7, 91-99, doi:10.5194/os7-91-2011, 2011.

Roether, W. and Schlitzer, R.: Eastern Mediterranean deep water renewal on the basis of chlorofluoromethane and tritium data, Dynam. Atmos. Oceans, 15, 333-354, 1991.

Roether, W., Schlosser, P., Kuntz, R., and Weiss, W.: Transienttracer studies of the thermohaline circulation of the Mediterranean, Reports in Meteorology and Oceanography, 41, 291-317, 1992.

Roether, W., Manca, B., Klein, B., Bregant, D., Georgopoulos, D., Beitzel, V., Kovacevic, V., and Luchetta, A.: Recent Changes in Eastern Mediterranean Deep Waters, Science, 271, 333-335, 1996.

Roether, W., Klein, B., Beitzel, V., and Manca, B.: Property distributions and transient-tracer ages in Levantine Intermediate Water in the Eastern Mediterranean, J. Marine Syst., 18, 71-87, 1998.

Roether, W., Klein, B., Manca, B. B., Theocharis, A., and Kioroglou, S.: Transient Eastern Mediterranean deep waters in response to the massive dense-water output of the Aegean Sea in the 1990s, Prog. Oceanogr., 74, 540-571, doi:10.1016/j.pocean.2007.03.001, 2007.
Roether, W., Jean-Baptiste, P., Fourrè, E., and Sültenfuß, J.: The transient distribution of nuclear weapon-generated tritium and its decay product ${ }^{3} \mathrm{He}$ in the Mediterranean Sea, 1952-2011, and their oceanographic potential, Ocean Sci., 9, 837-854, doi:10.5194/os-9-837-2013, 2013.

Rubino, A. and Hainbucher, D.: A large abrupt change in the abyssal water masses of the eastern Mediterranean, Geophys. Res. Lett., 34, L23607, doi:10.1029/2007GL031737, 2007.

Schlitzer, R., Roether, W., Oster, H., Junghans, H., Hausmann, M., Johannsen, H., and Michelato, A.: Chlorofluoromethane and oxygen in the Eastern Mediterranean, Deep Sea Res.-Pt. A, 38, 1531-1551, 1991.

Schneider, A., Tanhua, T., Koertzinger, A., and Wallace, D.: High anthropogenic carbon content in the eastern Mediterranean, J. Geophys. Res., 115, C12050, doi:10.1029/2010JC006171, 2010.

Schneider, A., Tanhua, T., Koertzinger, A., and Wallace, D.: An evaluation of tracer fields and anthropogenic carbon in the equatorial and the tropical North Atlantic, Deep Sea Res.-Pt. I, 67, 85-97, doi:10.1016/j.dsr.2012.05.007, 2012.

Schneider, A., Tanhua, T., Roether, W., and Steinfeldt, R.: Changes in ventilation of the Mediterranean Sea during the past 25 year, Ocean Sci., 10, 1-16, doi:10.5194/os-10-1-2014, 2014

Schroeder, K., Gasparini, G., Tangherlini, M., and Astraldi, M.: Deep and intermediate water in the western Mediterranean under the influence of the Eastern Mediterranean Transient, Geophys Res. Lett., 33, L21607, doi:10.1029/2006GL027121, 2006.

Schroeder, K., Ribotti, A., Borghini, M., Sorgente, R., Perilli, A., and Gasparini, G.: An extensive western Mediterranean deep water renewal between 2004 and 2006, Geophys. Res. Lett., 35, L18605, doi:10.1029/2008GL035146, 2008.

Schroeder, K., Josey, S., Herrmann, M., Grignon, L., Gasparini, G., and Bryden, H.: Abrupt warming and salting of the Western Mediterranean Deep Water after 2005: Atmospheric forcings and lateral advection, J. Geophys. Res., 115, C08029, doi:10.1029/2009JC005749, 2010.

Steinfeldt, R.: Ages and age spectra of Eastern Mediterranean Deep Water, J. Marine Syst., 48, 67-81, 2004.

Stöven, T.: Ventilation processes of the Mediterranean Sea based on CFC-12 and $\mathrm{SF}_{6}$ measurements, GEOMAR OceanRep, available at: http://oceanrep.geomar.de/id/eprint/13936 (last access: 1 June 2014), diploma thesis, Christian-Albrechts-Universität zu Kiel, 2011.

Sültenfuß, J., Roether, W., and Rhein, M.: The Bremen mass spectrometric facility for the measurement of helium isotopes, neon, and tritium in water, Isot. Environ. Health Stud., 45, 1-13, 2009.

Tanhua, T., Waugh, D., and Wallace, D.: Use of $\mathrm{SF}_{6}$ to estimate anthropogenic $\mathrm{CO}_{2}$ in the upper ocean, J. Geophys. Res., 113, 2156-2202, doi:10.1029/2007JC004416, 2008.

Tanhua, T., Hainbucher, D., Cardin, V., Álvarez, M., Civitarese, G., McNichol, A. P., and Key, R. M.: Repeat hydrography in the Mediterranean Sea, data from the Meteor cruise 84/3 in 2011, Earth Syst. Sci. Data, 5, 289-294, doi:10.5194/essd-5-289-2013, 2013a.

Tanhua, T., Hainbucher, D., Schroeder, K., Cardin, V., Álvarez, M., and Civitarese, G.: The Mediterranean Sea system: a review and an introduction to the special issue, Ocean Sci., 9, 789-803, doi:10.5194/os-9-789-2013, 2013b.

Tanhua, T., Waugh, D., and Bullister, J.: Estimating changes in ocean ventilation from the early 1990s CFC-12 and 
late $\mathrm{SF}_{6}$ measurements, Geophys. Res. Lett., 40, 927-932, doi:10.1002/grl.50251, 2013c.

Taylor, C. and Roether, W.: A uniform scale to report low-level tritium measurements in water, Int. J. Appl. Radiat. Is., 33, 377382, 1982.

Unterweger, M., Coursey, B., Schima, F., and Mann, W.: Preparation and calibration of the 1987 National Bureau of Standards tritiated-water standards, Int. J. Appl. Radiat. Is., 31, 611-614, 1980.

Vollmer, M. and Weiss, R.: Simultaneous determination of sulfur hexafluoride and three chlorofluorocarbons in water and air, Mar. Chem., 78, 137-148, 2002.

Walker, S. J., Weiss, R. F., and Salameh, P. K.: Reconstructed histories of the annual mean atmospheric mole fractions for the halocarbons CFC-11 CFC-12, CFC-113, and carbon tetrachloride, J. Geophys. Res.-Oceans, 105, 14285-14296, doi:10.1029/1999JC900273, 2000.

Warner, M. and Weiss, R.: Solubilities of chlorofluorocarbons 11 and 12 in water and seawater, Deep Sea Res.-Pt. A, 32, 14851497, 1985.
Watson, A., Messias, M.-J., Fogelqvist, E., Van Scoy, K., Johannessen, T., Oliver, K., Stevens, D., Rey, F., Tanhua, T., Olsson, K., Carse, F., Simonsen, K., Ledwell, J., Jansen, E., Cooper, D., Kruepke, J., and Guilyardi, E.: Mixing and convection in the Greenland Sea from a tracer-release experiment, Nature, 401, 902-904, doi:10.1038/44807, 1999.

Waugh, D. W., Vollmer, M. K., Weiss, R. F., Haine, T. W. N., and Hall, T. M.: Transit time distributions in Lake Issyk-Kul, Geophys. Res. Lett., 29, 84.1-84.4, doi:10.1029/2002GL016201, 2002.

Waugh, D., Hall, T., and Haine, T.: Relationships among tracer ages, J. Geophys. Res., 108, 3138, doi:10.1029/2002JC001325, 2003.

Waugh, D., Haine, T. W., and Hall, T. M.: Transport times and anthropogenic carbon in the subpolar North Atlantic Ocean, Deep Sea Res.-Pt. I, 51, 1475-1491, 2004.

Waugh, D., Hall, T., McNeil, B., Key, R., and Matear, R.: Anthropogenic $\mathrm{CO}_{2}$ in the oceans estimated using transit time distributions, Tellus B, 58, 376-389, 2006.

Wuest, G.: On the vertical circulation of the Mediterranean Sea, J. Geophys. Res., 66, 3261-3271, 1961. 